\title{
Non-Invasive Follicular Thyroid Neoplasm with Papillary-Like Nuclear Features Is Not a Cytological Diagnosis, but It Influences Cytological Diagnosis Outcomes: A Systematic Review and Meta-Analysis
}

\author{
Elina Haaga ${ }^{a, b}$ David Kalfert ${ }^{c}$ Marie Ludvíkovád Ivana Kholováa, b \\ aPathology, Fimlab Laboratories, Tampere, Finland; ${ }^{\mathrm{b}}$ Tampere University, Faculty of Medicine and Health \\ Technology, Tampere, Finland; ' Department of Otorhinolaryngology and Head and Neck Surgery, First Faculty of \\ Medicine, Charles University, University Hospital Motol, Prague, Czech Republic; ${ }^{\mathrm{d}}$ Department of Biology, Faculty of \\ Medicine in Pilsen, Charles University, Pilsen, Czech Republic
}

\section{Keywords}

Non-invasive follicular thyroid neoplasm with papillary-like nuclear features - Thyroid gland - The Bethesda System for Reporting Thyroid Cytology · Cytomorphology · Metaanalysis

\begin{abstract}
Background: A low-risk thyroid tumour, non-invasive follicular thyroid neoplasm with papillary-like nuclear features (NIFTP) was introduced in 2016. NIFTP criteria require a thorough histological examination to rule out capsular and lymphovascular invasion, which denies the possibility of preoperative cytological diagnosis. Nevertheless, since the adoption of the new entity, the cytology of NIFTP has been a subject of interest. Objectives: The present systematic review and meta-analysis investigate the cytological diagnosis of NIFTP. Method: An online PubMed literature search was conducted between March 1, 2020, and June 30, 2020, for all original articles considering the cytology of histologically proven NIFTP. The studies including data on fine needle aspiration specimens classified by The Bethesda System for Reporting Thyroid Cytology (TBSRTC) categories, risk of malignancy (ROMs) in the TBSRTC categories, and cytomorpho-
\end{abstract}

logical features of NIFTP were included in the meta-analysis. Non-English studies and case reports were excluded. The data were tabulated and statistical analysis was performed with Open Meta-Analyst program. Results: Fifty-eight studies with a total of 2,553 NIFTP cases were included in the study. The pooled prevalence of NIFTP cases was calculated among 25,892 surgically resected cases from 20 studies and the results show that NIFTP consisted $4.4 \%$ (95\% confidence interval [Cl]: 3.5-5.4\%) of all cases. Most of the NIFTP cases (79.0\%) belonged to the intermediate categories of TBSRTC. The pooled distribution of NIFTP cases in each TBSRTC category was $1.3 \%$ (95\% Cl: $0.8-1.7 \%$ ) in non-diagnostic (ND), 8.9\% (95\% Cl: $6.9-10.8 \%$ ) in benign, $29.2 \%$ (95\% Cl: $25.0-$ $33.4 \%$ ) in atypia of undetermined significance or follicular lesion of undetermined significance (AUS/FLUS), 24.2\% (95\% Cl: 19.6-28.9\%) in follicular neoplasm (FN), 19.5\% (95\% Cl: $16.1-22.9 \%$ ) in suspicious for malignancy (SM), and 6.9\% (95\% Cl: 5.2-8.7\%) in malignant. Compared to pre-NIFTP era, the pooled risk differences of ROM were reduced by $2.4 \%$ in $\mathrm{ND}, 2.7 \%$ in benign, $8.2 \%$ in AUS/FLUS, $8.2 \%$ in $\mathrm{FN}, 7.3 \%$ in SM, and $1.1 \%$ in the malignant category. The cytomorphological features of NIFTP were similar to follicular variant of papillary thyroid carcinoma (FVPTC) but lesser to papillary thyroid carcinoma (PTC). Conclusions: Based on our results, karger@karger.com www.karger.com/acy

Karger $\stackrel{\text { ' }}{5}$ BOPEN ACCESS
(C) 2021 The Author(s)

Published by S. Karger AG, Basel

This is an Open Access article licensed under the Creative Commons Attribution-NonCommercial-4.0 International License (CC BY-NC) (http://www.karger.com/Services/OpenAccessLicense), applicable to the online version of the article only. Usage and distribution for commercial purposes requires written permission.
Correspondence to:

Marie Ludvíková, marie.ludvikova @lfp.cuni.cz 
NIFTP remains a histological diagnosis. Although cytomorphological features cannot be used in differentiating NIFTP from FVPTC, they may guide in separating NIFTP from PTC. Features such as papillae, microfollicles, giant cells, psammoma bodies, and the amount of papillary-like nuclear features should be taken into account when suspicious of NIFTP. NIFTP should not have papillae or psammoma bodies, and giant cells were rarely observed.

(c) 2021 The Author(s).

Published by S. Karger AG, Basel

\section{Introduction}

Thyroid tumours are the most common endocrine neoplasms. The number of diagnosed thyroid tumours increased in the last decades, while mortality rates remained at the same level $[1,2]$. This is partially explained by overdiagnosing and the slow progression and indolent behaviour of the tumours $[3,4]$. Papillary thyroid carcinoma (PTC) is the most common thyroid malignancy, and it is solely responsible for the increase in the thyroid tumour incidence $[2,5]$. Follicular variant of papillary thyroid carcinoma (FVPTC) contributes to a large portion of papillary carcinomas and covers over $20 \%$ of all thyroid tumours in Europe and North America [6]. FVPTC is divided into encapsulated and infiltrative variants [1]. The non-invasive encapsulated variant has an indolent clinical behaviour with only few adverse outcomes, contradictory to the fact that the entity was classified as malignant [6-10].

In 2016, an international group of experienced endocrine pathologists introduced a new low-risk tumour entity, non-invasive follicular thyroid neoplasm with papillary-like nuclear features (NIFTP) [11]. NIFTP was included in the fourth edition of the World Health Organization classification of tumours of endocrine organs [1] and in the guidelines of the American Thyroid Association [12], which led to the general adoption of the new entity. Prior to the nomenclature change, NIFTP cases were usually classified as non-invasive encapsulated form of FVPTC, covering a significant portion of that group, although elsewhere in many parts of the world including Asia and the UK, the majority of cases that now meet the World Health Organization 2017 criteria for NIFTP were most frequently diagnosed as follicular adenoma. It was estimated that over 45,000 patients all around the world would now be diagnosed with NIFTP yearly [11].

As a neoplasm with an extremely low malignant potential, NIFTP should not be a metastatic or recurrent tumour [13]. Since NIFTP is no longer considered a cancer, the reclassification will decrease the amount of overdiagnoses, overtreatment, the need of surveillance, and the psychological and financial burden on patients diagnosed with NIFTP. NIFTP cases ought to be treated in a more risk-appropriate way which reduces the complications associated with total thyroidectomy and radioactive iodine therapy $[6,11,14]$. The elimination of the label "cancer" will have a significant psychosocial effect on the patients and will reduce the stigma of NIFTP diagnosis, since patients commonly associate cancer with inevitable progression, metastases, and possible death $[15,16]$.

After being revised in 2018, the diagnostic criteria of NIFTP were grouped into the primary and the secondary criteria. The primary criteria are required for the diagnosis of NIFTP. The secondary criteria are not necessary but may guide the diagnosis. The primary criteria for NIFTP diagnosis include encapsulation or clear demarcation of the tumour with no vascular or capsular invasion at histological examination, follicular growth pattern with no well-formed papillae, no psammoma bodies, and $<30 \%$ of solid, trabecular, or insular growth pattern. A nuclear score of 2 or 3 is needed, and tumour necrosis or high mitotic activity should be absent. The secondary criteria include the lack of $\mathrm{BRAF}^{\mathrm{V} 600 \mathrm{E}}$ mutation, $\mathrm{BRAF}^{\mathrm{V} 600 \mathrm{E}}$-like mutations, or other high-risk mutations detected by molecular assays or immunohistochemistry $[11,17,18]$.

Since the diagnostic criteria require a histological examination, NIFTP is not a cytological diagnosis. Nevertheless, since the introduction of the new entity, cytology of NIFTP has been a subject of interest. Thyroid fine needle aspiration (FNA) biopsies are categorized using The Bethesda System for Reporting Thyroid Cytopathology (TBSRTC) [19]. NIFTP cases generally belong to the intermediate categories of TBSRTC $[8,20-$ 26]. The nomenclature revision affects the calculated risks of malignancy (ROM) in the TBSRTC categories. Since NIFTP is no longer considered malignant, the ROM decreased especially in the intermediate categories, where the underlying prevalence of EFVPTC is high $[20,25,27-29]$. With low rates of diagnosis of EFVPTC and NIFTP, the effect on the rates of diagnosis and ROM in the various indeterminate categories is expected to be low or negligible.

Given the novelty of the entity, meta-analyses with only moderately small sample sizes have been made and the cytological diagnosing of NIFTP still remains uncertain. The present meta-analysis is conducted to study the cytological diagnosing of cases histologically confirmed as NIFTP. For example, we scoped on the 
Fig. 1. A flow chart displaying the study selection process. OR, odds ratio; NIFTP, non-invasive follicular thyroid neoplasm with papillary-like nuclear features; TBSRTC, The Bethesda System for Reporting Thyroid Cytopathology.
Search results from PubMed using the search terms ("noninvasive follicular thyroid neoplasm with papillary like features" OR

"NIFTP") AND ("cytology" OR "risk of

malignancy" OR "cytomorphology") prior 30th June 2020 $n=173$
Manually inspected citations of relevant meta-analyses / studies included in this meta-analysis

Reasons for exclusion:

- Non-English studies

- Case reports

- Reviews and Meta-analyses

- Studies not considering the

Studies chosen for full text reading study subject

Reasons for exclusion:

- Strict NIFTP-criteria not used

- TBSRTC not used

- No data of TBSRTC

Studies included in this meta-analysis categorization, ROM or cytomorphology

TBSRTC categorization, ROM changes, and cytomorphological features. In addition, we calculated NIFTP prevalence and compared the incidence in the different TBSRTC categories.

\section{Methods}

A PubMed literature search was done between March 1, 2020, and June 30, 2020, to identify all suitable original articles. The search was aimed to detect original studies on the cytology of NIFTP. The terminologies used for the search were ("non-invasive follicular thyroid neoplasm with papillary like nuclear features" or "NIFTP") and ("cytology" or "cytomorphology" or "risk of malignancy"). To expand the search, the citations of the included studies and relevant meta-analyses were also manually inspected for potential articles during the previously mentioned dates.

All the studies were screened independently by 1 reviewer (E.H.). Any unclear questions were discussed with another reviewer (I.K.). The titles and abstracts were screened for the potential data related to our study subject. If the article seemed to be relevant to the study, full text was screened for the inclusion and exclusion criteria. Studies were included if they fulfilled the following criteria: (1) strict NIFTP criteria were used and thorough histological investigations were performed, and (2) FNA biopsies were categorized using TBSRTC, and (3) the study included adequate data about FNA cytology results, ROMs according to the TBSRTC categories or cytomorphology. Non-English language articles and case reports were excluded. The selection process is displayed in a flowchart (Fig. 1).

Cytopathology of NIFTP: Meta-Analysis
The following data were extracted in a standardized form from the articles by 1 reviewer (E.H.): first author, year of publication, geographical area, study design (prospective vs. retrospective), study population (institutional vs. multi-institutional), inclusion criteria, time period, staining and preparation methods, number of FNA biopsies, number of surgically resected nodules, histological diagnoses, TBSRTC categories, cytomorphological features, and calculated ROM.

The observed and described cytomorphological nuclear features were nuclear pseudoinclusions, crowding, enlargement, contour irregularities, elongation, grooves, and chromatin clearing. In addition, the presence of giant cells, psammoma bodies, microfollicles, and papillae was documented. If the articles contained data considering cytomorphology of FVPTC or PTC, the relevant facts were also extracted and included in the analysis. The data were collected in Microsoft Excel.

The ROMs were calculated in 2 ways: considering NIFTP as a malignant entity and as a non-malignant tumour. The decrease of ROM after the reclassification was also calculated. If the study included data of both actual ROMs (malignant cases - NIFTP cases/ all surgically resected cases) and overall ROMs (malignant cases NIFTP cases/all FNA samples), only the actual ROM was extracted.

Considering the fact that the majority of the studies were expected to be retrospective reviews of cytology databases, the possibility of missing data in some variables was allowed in the systematic review. Missing data were reported as "N.D." If studies had missing data on relevant variables, they were excluded from metaanalysis calculations.

Mean, minimum, and maximum values and SEM were calculated in each category. The prevalence of each cytomorphological feature was calculated from mean incidence. The NIFTP preva- 
lence was also calculated. A summary of the included studies, the distribution of TBSRTC categories, and the presence of cytomorphological features among NIFTP cases were tabulated and the studies were displayed in alphabetical order. The studies with data on ROMs were tabulated and organized by NIFTP incidence.

Statistical analysis was performed with Open Meta-Analyst program (source: http://www.cebm.brown.edu/openmeta/). The pooled data were calculated using a random-effects model and using the DerSimonian and Laird method. A random-effects model was used because of the differences in the study population. The presence or absence of heterogeneity was assessed using the $I^{2}$ (inconsistency index) and $\chi^{2}$ statistic. Egger's test was used for calculation of publication bias. A forest plot was constructed. For the pooled effect measure, a $p$ value $<0.05$ was considered statistically significant.

A comparative meta-analysis was performed to obtain the pooled prevalence of histologically proven NIFTP in all patients who underwent surgery from selected studies. This analysis included studies that had included either all resections and/or FNA diagnosed samples available in their study population. Studies that had included only certain tumour entities were excluded from this analysis. The pooled distribution of NIFTP cases in different TBSRTC categories was calculated among the studies with available data on TBSRTC categories.

Additionally, a risk difference (RD) meta-analysis was performed to evaluate the ROM difference when considering NIFTP as a malignant or benign entity in relation to preoperative TBSRTC classification. A meta-analysis of RD was performed in each category independently. The criteria for inclusion were relevant data (change of ROM, available data of the number of cases). To compare the change of ROM between subgroups (Asia vs. other countries; NIFTP incidence $<5 \%$ vs. $>5 \%$ ), Mann Whitney U test was used and $p$ values $<0.05$ were considered statistically significant.

A meta-analysis of studies with available cytomorphology data was conducted to determine odds ratios (OR) comparing cytomorphology features in NIFTP versus FVPTC and versus PTC. The Mantel-Haenszel method was used for calculating the weighted summary OR under the fixed-effects model. The heterogeneity statistic was incorporated to calculate the summary OR under the fixed-effects model and $p$ values $<0.05$ were considered statistically significant. This meta-analysis predominantly followed the PRISMA 2020 checklist with 27 items. Items 1-13e, 15, 16a, 17, 19-20c, and 22-27 were followed. Items 13f, 14, 16b, 18, 20d, and 21 were not followed due to lack of resources. The study was not registered at PROSPERO.

\section{Results}

\section{Summary of the Studies}

A total of 58 articles met the selection criteria and were included in the study analysis [20-24, 26, 28-79], all published between August 15, 2015, and June 30, 2020. The studied material included 296 study years, in which a total of 81,875 FNA biopsies and 32,629 nodule resections were performed. Among these, 2,553 NIFTP cases were recognized (3\% of the total number of FNA biopsies and
$8 \%$ of the resected nodules). On an average, a single study lasted for 5.5 years and consisted of 1,412 FNA biopsies, 583 resected nodules, and 45 NIFTP nodules.

The details of each study are shown in Table 1. While most of the studies were retrospective analyses of cytological and histological specimens, only 1 study by Strickland et al. [69] was prospective. Most of the articles (86\%) $[21,22,24,26,28-31,33-35,37-45,47,49-73,75,77-79]$ analysed data from a single institution with only $14 \%$ [20, $23,32,36,46,48,74,76]$ being multi-institutional. The articles originated from North America (55\%) [26, 28, 30, $31,34,39,40,42,44,47-49,51-60,62,64,65,67-70,72$, 74, 75], Asia (26\%) [21, 22, 32, 33, 36-38, 43, 46, 50, 61, $63,66,73,77]$, Europe (14\%) [23, 29, 35, 41, 45, 71, 78, 79], and South America (2\%) [24]. Two articles included data from both North America and Europe (3\%) [20, 76].

The pooled overall prevalence of NIFTP cases was calculated among 25,892 cases from 20 studies, which had included either all resections and/or FNA samples available in their study population. The results show that NIFTP cases consisted 4.4\% (95\% confidence interval [CI]: 3.5-5.4\%, $I^{2}$ was $97 \%$ ) of all resections (shown in Fig. 2).

Methodologically, $21 \%$ of the studies $[22,33,34,36$, $37,40,47,50,64,66,73,75]$ examined the previously diagnosed FVPTC cases to find the potential NIFTP cases and compared these 2 groups. The incidence of NIFTP in these studies was $35 \%$. In addition to FVPTC, NIFTP was compared with classic variant of PTC, FTC, follicular adenoma, and other benign nodules in various studies. In $19 \%$ of the studies [28, 41, 44, 45, 48, 49, 52-54, 62, 68], all resections with available FNA biopsy information were included and mean NIFTP prevalence was 5\%. Twelve per cent of the studies [20, 21, 43, 58, 63, 70, 77] included all of the available FNA samples, and the mean NIFTP prevalence was $1 \%$. Some studies included only certain categories of TBSRTC, that is, Strickland et al. [26] chose the resections of intermediate FNA samples. The NIFTP prevalence in this category was $30 \%$.

\section{TBSRTC Categories}

Fifty-five articles [20-24, 26, 28-48, 50-58, 60-75, 7779] with data on TBSRTC categories were analysed, and the data are presented in Table 2. Among the 65,115 FNA samples and 26,752 resected nodules, there were 2300 NIFTP nodules (3.5\% of the FNA samples and $8.6 \%$ of the resected nodules) with available TBSRTC categorization.

The majority of the NIFTP FNA specimens belonged in the intermediate categories of TBSRTC (atypia of undetermined significance or follicular lesion of undetermined significance (AUS/FLUS) - 29.8\%, follicular neo- 
岛

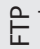

ষ্ّ

巛ّ

즐

ำ

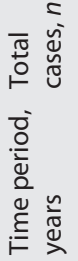

屯

造证

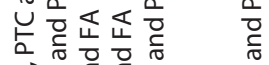

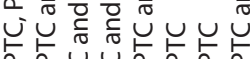

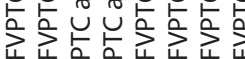

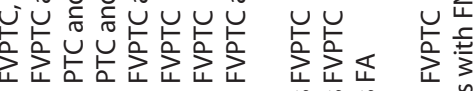

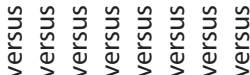

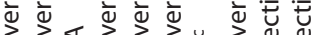

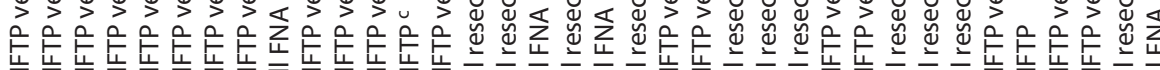

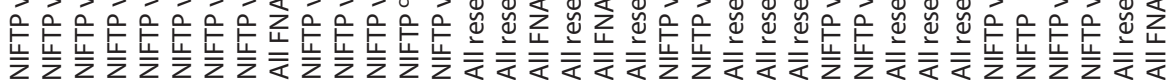


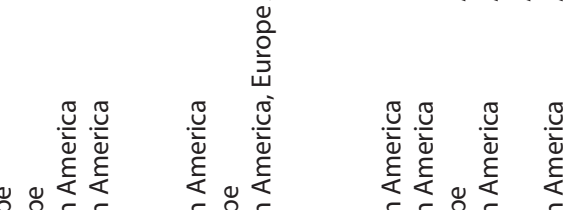

$\widehat{\circ}$

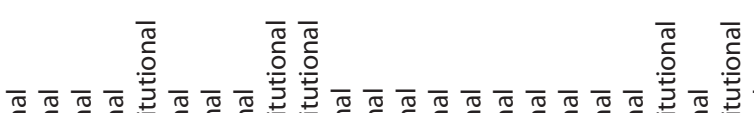

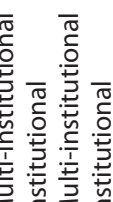

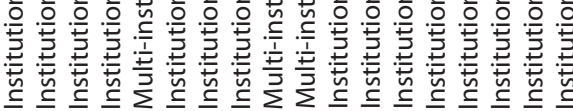

는 \begin{tabular}{l}
$\frac{5}{5}$ \\
$\frac{5}{2}$ \\
$\frac{0}{0}$ \\
$\frac{0}{\pi}$ \\
\hline
\end{tabular}

$\breve{\llcorner}$

$\sum^{2}$

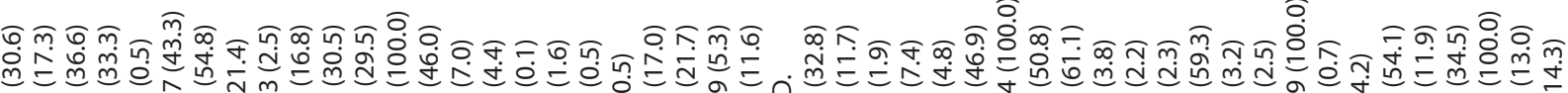
o.

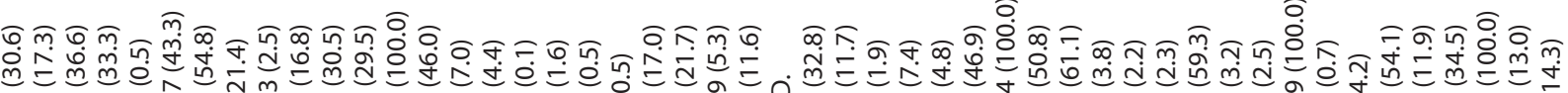

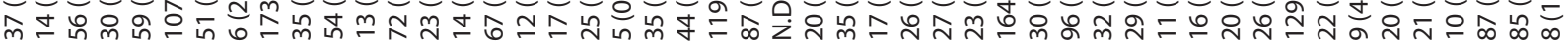

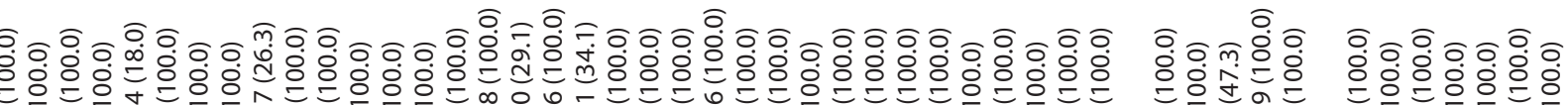

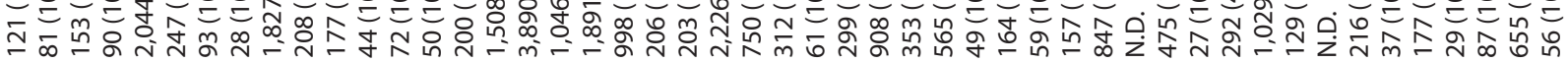

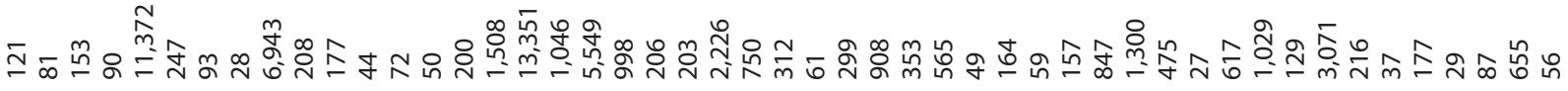
min

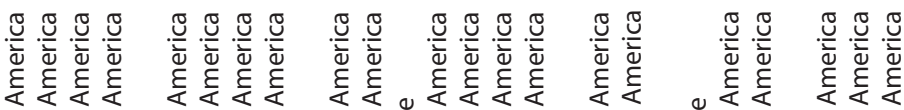

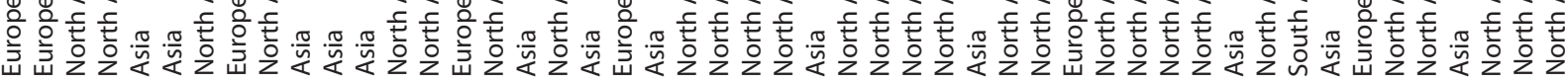

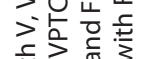

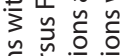

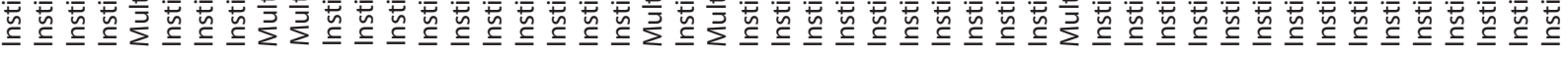

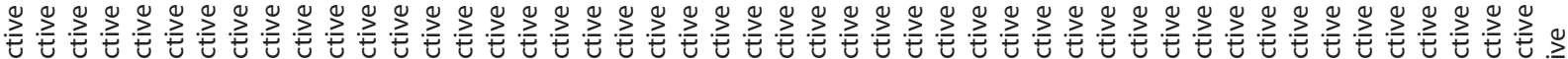

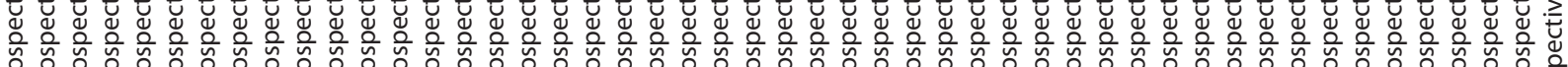

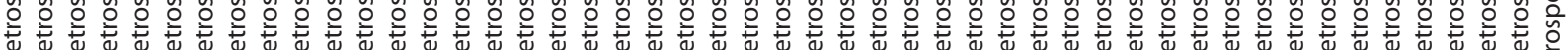

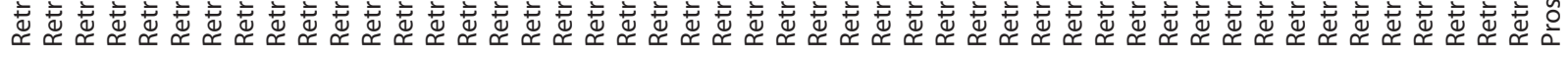

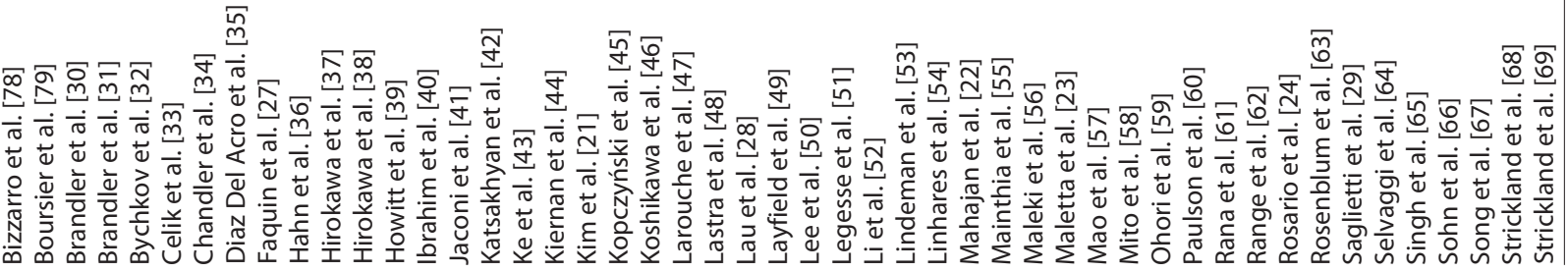




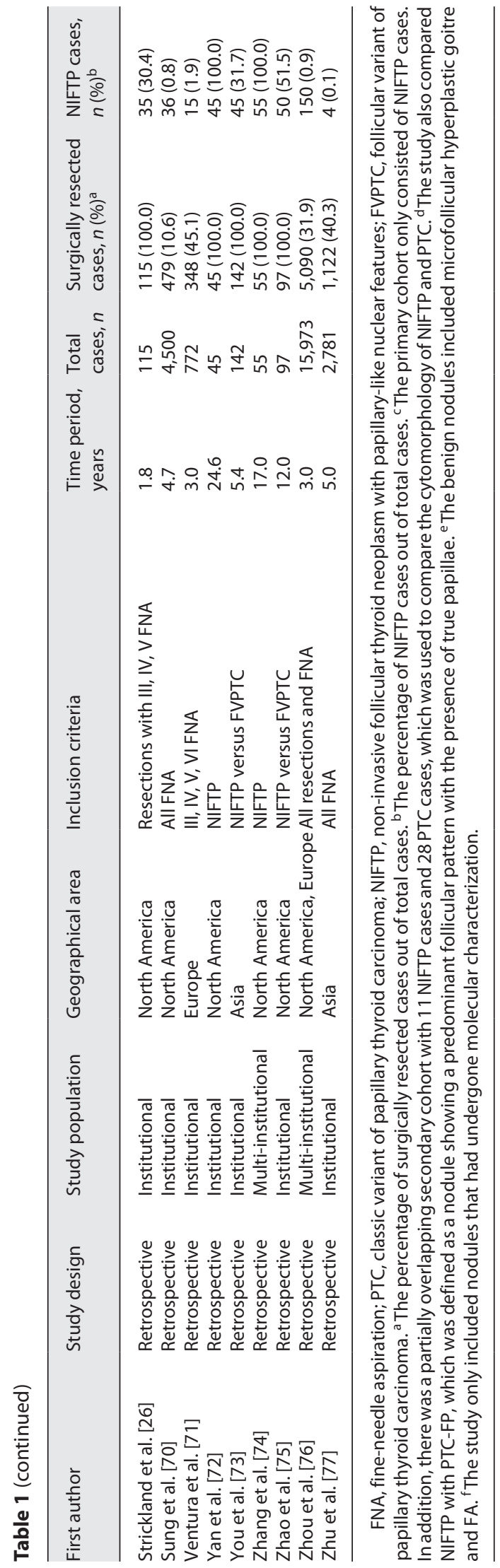

plasm (FN) $-28.0 \%$, and suspicious for malignancy (SM) $-21.2 \%$ ). Nevertheless, $1.8 \%$ of the samples belonged to the non-diagnostic (ND) category, $10.2 \%$ to the benign category, and $8.4 \%$ to the malignant category.

The pooled distribution of NIFTP cases in each TBSRTC category was $1.3 \%$ (95\% CI: $0.8-1.7 \%, I^{2}$ was $0 \%$ ) in $\mathrm{ND}, 8.9 \%$ (95\% CI: $6.9-10.8 \%, I^{2}$ was $71 \%$ ) in benign, 29.2\% (95\% CI: $25.0-33.4 \%, I^{2}$ was $82 \%$ ) in AUS/FLUS, $24.2 \%$ (95\% CI: $19.6-28.9 \%, I^{2}$ was $89 \%$ ) in FN, $19.5 \%$ (95\% CI: $16.1-22.9 \%, I^{2}$ was $\left.80 \%\right)$ in SM, and $6.9 \%(95 \%$ CI: $5.2-8.7 \%, I^{2}$ was $\left.76 \%\right)$ in malignant. The data of the pooled distributions are displayed in Figure 3 and individually in online supplement 1, Figs. 1-6 (see www. karger.com/doi/10.1159/000519757 for all online suppl. material).

\section{Risk of Malignancy}

Twenty-two articles $[20,21,28,32,43-45,49,52-54$, $57-59,61-63,68,70,71,76,77]$ with data on ROMs of the TBSRTC categories were analysed, and the data are presented in Table 3. Among 24,921 surgical resections, there were 878 (3.5\%) histologically proven NIFTP cases.

If NIFTP would be considered a malignant entity, the mean ROMs would have been the following: $28.9 \%$ for ND, $12.7 \%$ for benign, $36.6 \%$ for AUS/FLUS, $35.1 \%$ for FN, $82.8 \%$ for SM, and $97.7 \%$ for malignant. Considering NIFTP as a non-malignant tumour, the average ROMs were $26.9 \%$ for ND, $9.2 \%$ for benign, $29.2 \%$ for AUS/ FLUS, $26.1 \%$ for FN, $71.7 \%$ for SM, and $95.9 \%$ for malignant. Risks decreased in all TBSRTC categories, and the mean absolute decrease for each category was $1.9 \%, 3.4 \%$, $7.5 \%, 8.9 \%, 11.1 \%$, and $2.1 \%$, respectively. The decrease was most visible for the intermediate categories of TBSRTC, which supports the fact that most NIFTP cases are classified in the intermediate TBSRTC categories.

Meta-analyses of pooled RDs of ROM were performed in each TBSRTC category independently (shown in online suppl. 2, Fig. 7-12), and the results are displayed in Figure 4 . Risk differences of ROM were reduced by $2.4 \%$ $\left(I^{2}\right.$ was $0 \%$ ) in ND, $2.7 \%$ ( $I^{2}$ was $2 \%$ ) in benign, $8.2 \%$ ( $I^{2}$ was $\left.43 \%\right)$ in AUS/FLUS, $8.2 \%$ ( $I^{2}$ was $53 \%$ ) in FN, 7.3\% ( $I^{2}$ was $\left.89 \%\right)$ in SM, and $1.1 \%$ ( $I^{2}$ was $\left.45 \%\right)$ in the malignant categories.

Sub-analyses of ROM were performed including either only Asian studies or studies conducted elsewhere in the world (online suppl. 2, Fig. 13-24). In Asia, the RDs of ROM were reduced by $2.6 \%\left(I^{2}\right.$ was $\left.0 \%\right)$ in ND, $2.7 \%$ $\left(I^{2}\right.$ was $0 \%$ ) in benign, $4.7 \%$ ( $I^{2}$ was $0 \%$ ) in AUS/FLUS, $6.0 \%\left(I^{2}\right.$ was $\left.45 \%\right)$ in $\mathrm{FN}, 1.8 \%\left(I^{2}\right.$ was $\left.29 \%\right)$ in SM, and $0.3 \%$ ( $I^{2}$ was $28 \%$ ) in malignant category. In other coun- 


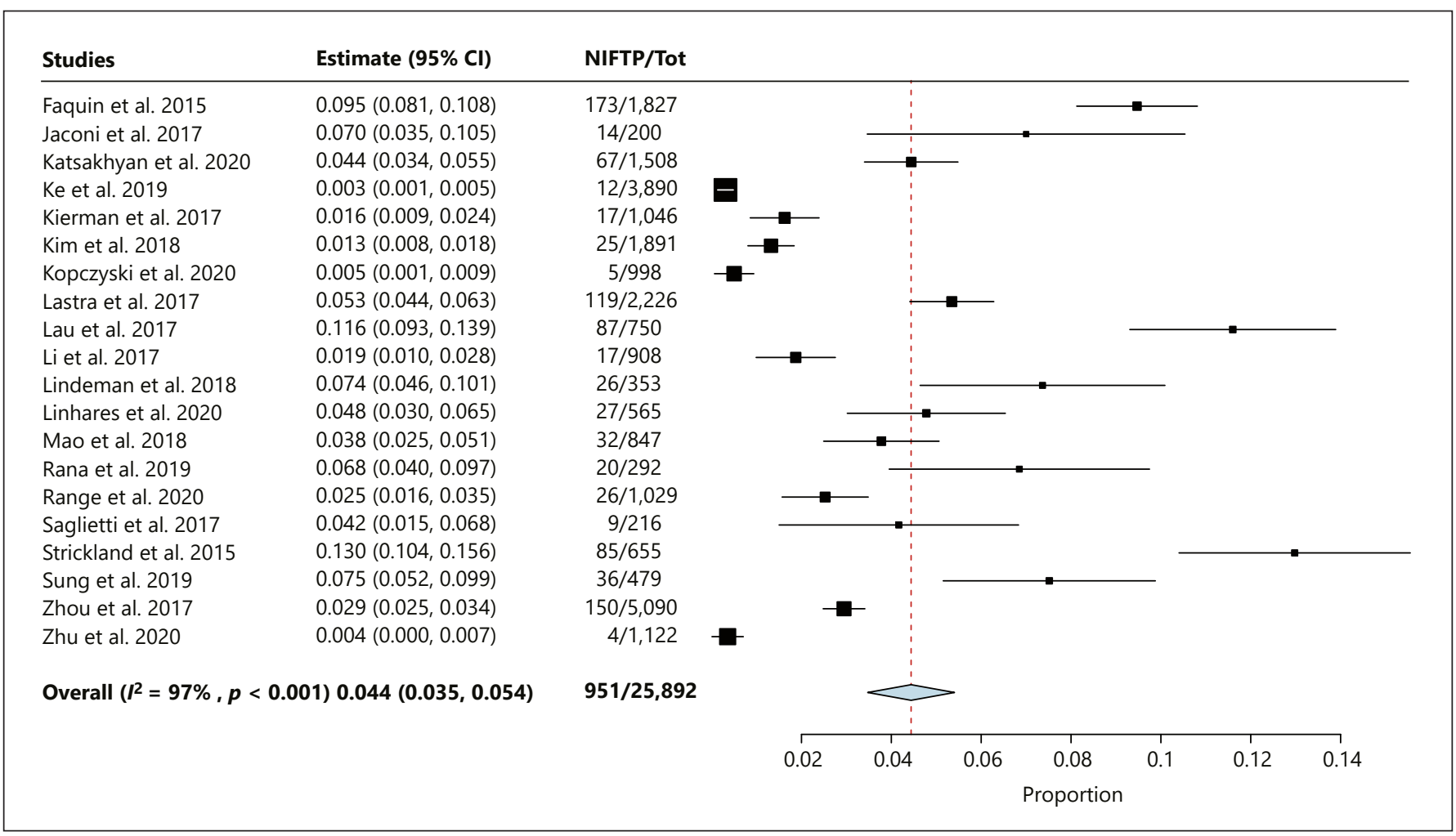

Fig. 2. The pooled prevalence of NIFTP cases among 24,384 cases from 19 studies which had included either all resections or FNA diagnosed samples available in their study population. The results show that NIFTP consisted $4.4 \%$ (95\% CI from 3.5\% to $5.4 \%$ ) of all surgically resected cases. $I^{2}$ (inconsistency index) was $97 \%$. NIFTP, non-invasive follicular thyroid neoplasm with papillarylike nuclear features; FNA, fine needle aspiration; CI, confidence interval.

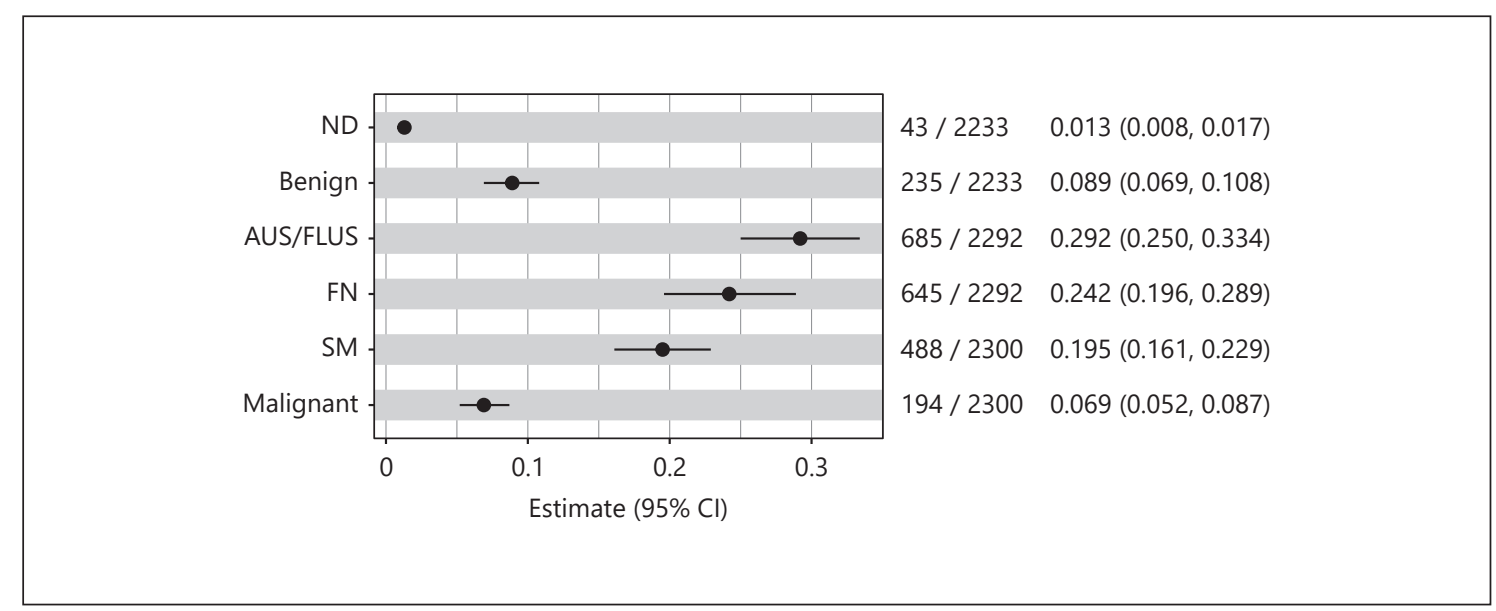

Fig. 3. The overall pooled distribution of NIFTP cases in preoperative FNA TBSRTC categories. The pooled prevalence of the categories were the following: ND $1.3 \%$ (95\% CI from $0.8 \%$ to $1.7 \%$, $I^{2}$ was $0 \%$ ), benign $8.9 \%$ ( $95 \%$ CI from $6.9 \%$ to $10.8 \%, I^{2}$ was $71 \%$ ), AUS/FLUS $29.2 \%$ (95\% CI from $25.0 \%$ to $33.4 \%, I^{2}$ was $82 \%$ ), FN $24.2 \%$ (95\% CI from $19.6 \%$ to $28.9 \%, I^{2}$ was $89 \%$ ), SM $19.5 \%(95 \%$ CI from $16.1 \%$ to $22.9 \%, I^{2}$ was $80 \%$ ), and malignant $6.9 \%$ (95\% CI from $5.2 \%$ to $8.7 \%, I^{2}$ was $76 \%$ ). NIFTP, non-invasive follicular thyroid neoplasm with papillary-like nuclear features; TBSRTC, The Bethesda System for Reporting Thyroid Cytopathology; FNA, fine needle aspiration; CI, confidence interval; AUS/FLUS, atypia of undetermined significance or follicular lesion of undetermined significance; FN, follicular neoplasm; SM, suspicious for malignancy; ND, non-diagnostic. 


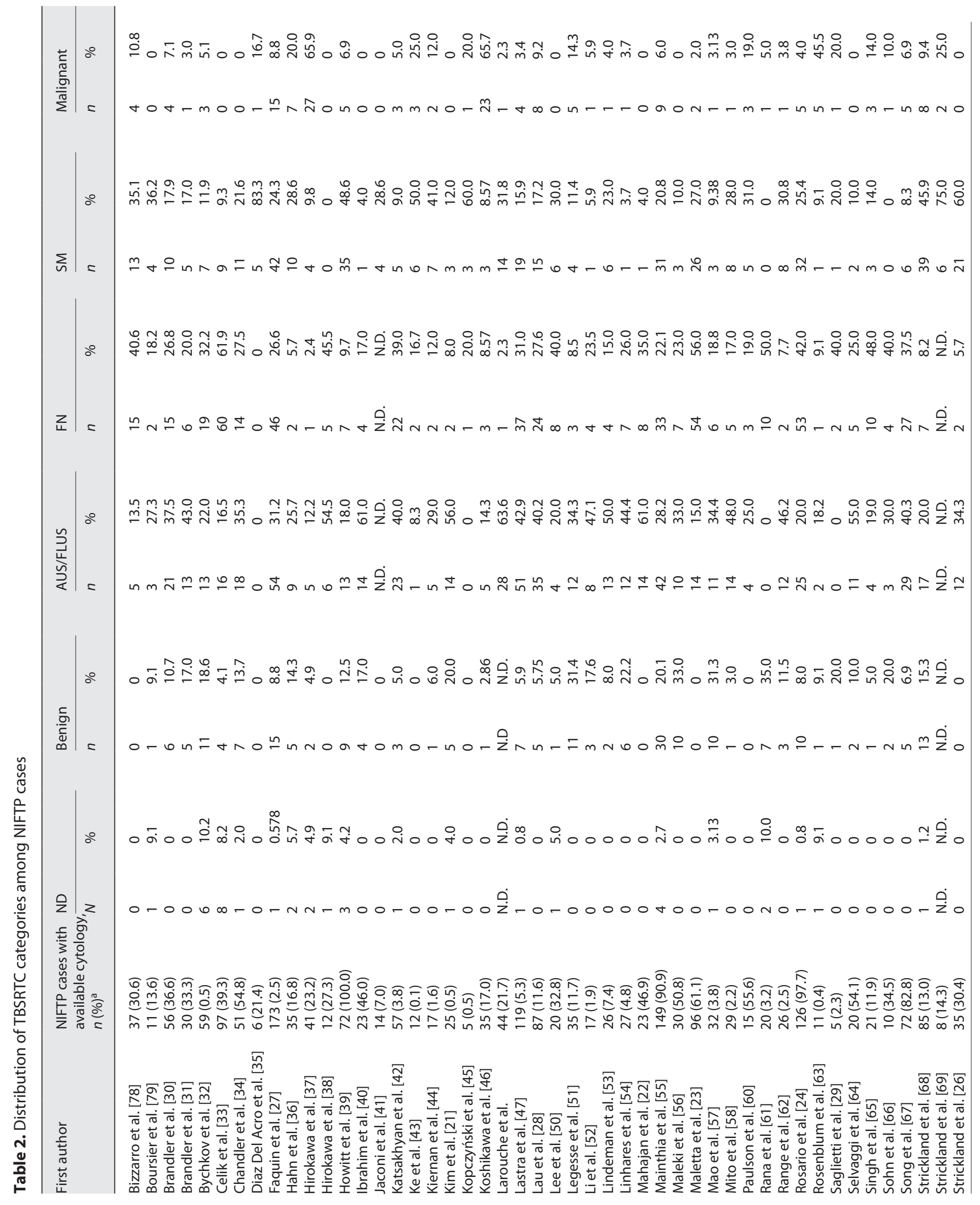




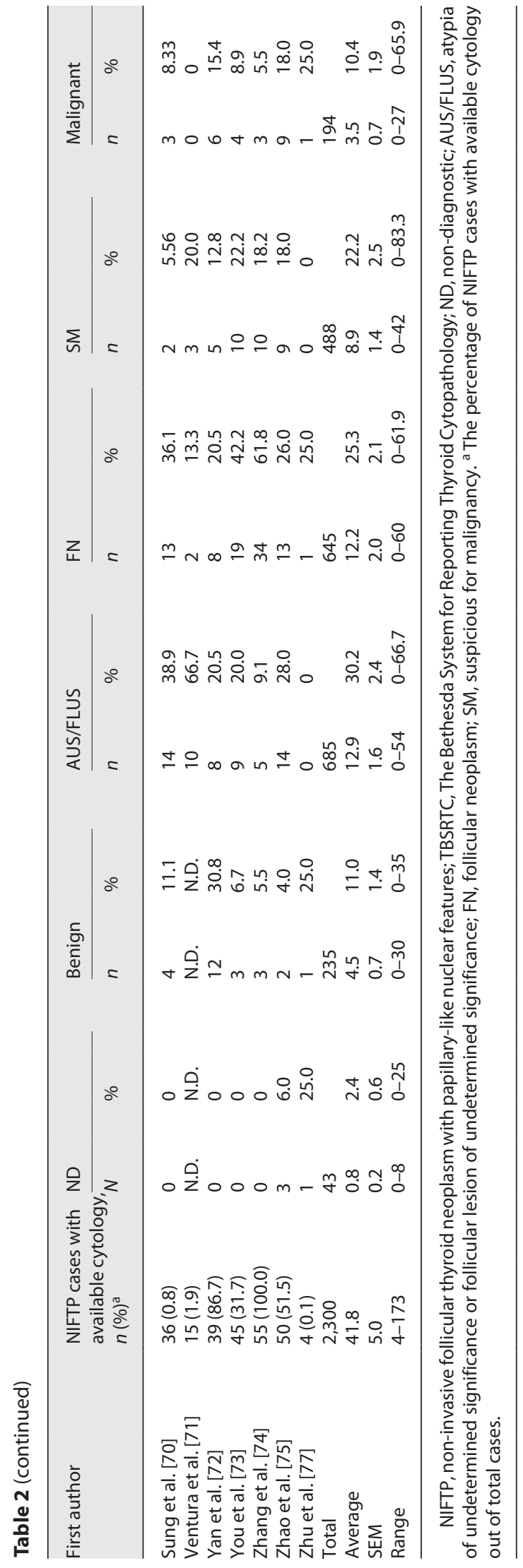

Cytopathology of NIFTP: Meta-Analysis

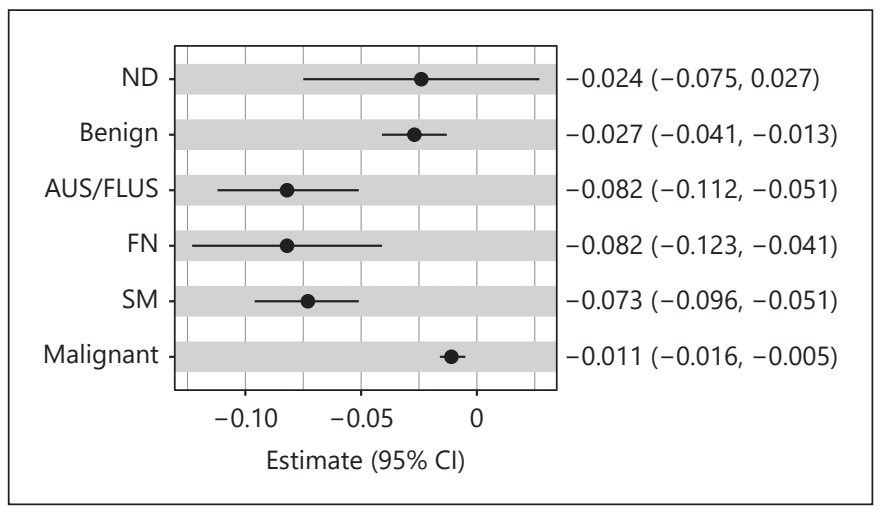

Fig. 4. The overall pooled RDs of ROM in TBSRTC categories considering NIFTP a non-malignant tumour. The inclusion criteria in these studies were relevant data for analysis (change of ROM, available data of the number of NIFTP cases). The ROM was reduced by $2.4 \%$ ( $I^{2}$ was $0 \%$ ) in ND, $2.7 \%\left(I^{2}\right.$ was $2 \%$ ) in benign, $8.2 \%$ $\left(I^{2}\right.$ was $\left.43 \%\right)$ in AUS/FLUS, $8.2 \%\left(I^{2}\right.$ was $\left.53 \%\right)$ in FN, $7.3 \%\left(I^{2}\right.$ was $89 \%)$ in SM, and $1.1 \%$ ( $I^{2}$ was $\left.45 \%\right)$ in malignant category. NIFTP, non-invasive follicular thyroid neoplasm with papillary-like nuclear features; TBSRTC, The Bethesda System for Reporting Thyroid Cytopathology; ND, non-diagnostic; AUS/FLUS, atypia of undetermined significance or follicular lesion of undetermined significance; FN, follicular neoplasm; SM, suspicious for malignancy; ROM; risk of malignancy; $\mathrm{RD}$, risk difference.

tries, the corresponding numbers were $1.9 \%\left(I^{2}\right.$ was $\left.0 \%\right)$ in ND, $1.9 \%\left(I^{2}\right.$ was $\left.5 \%\right)$ in benign, $9.7 \%\left(I^{2}\right.$ was $\left.52 \%\right)$ in AUS/FLUS, $9.1 \%$ ( $I^{2}$ was $27 \%$ ) in FN, $14.7 \%\left(I^{2}\right.$ was $\left.73 \%\right)$ in $\mathrm{SM}$, and $1.7 \%$ ( $I^{2}$ was $0 \%$ ) in the malignant category. The differences were statistically significant in the AUS/ FLUS $(p=0.023), \mathrm{FN}(p=0.001)$, and malignant $(p=$ $0.008)$ categories.

Additionally, the differences on the change of ROM were examined between studies with over 5\% NIFTP incidence and below 5\% NIFTP incidence (online suppl. 2, Fig. 25-36). Statistically significant differences were observed in the AUS/FLUS and FN categories. In the AUS/ FLUS category, the mean decrease of ROM was $13.5 \%$ in studies with $>5 \%$ incidence and $5.1 \%$ in studies with $<5 \%$ incidence $(p=0.036)$. In the FN category, the corresponding numbers were $17.2 \%$ and $5.6 \%(p=0.005)$. In other TBSRTC categories, the differences were not statistically significant.

\section{Cytomorphological Features}

Eighteen articles [22, 23, 30, 34, 35, 37-39, 41, 46, 51, $56,64,69,72,74,78,79]$ with data on the cytomorphological features of NIFTP were analysed and the data are summarized in Table 4. Meta-analyses of the features are 


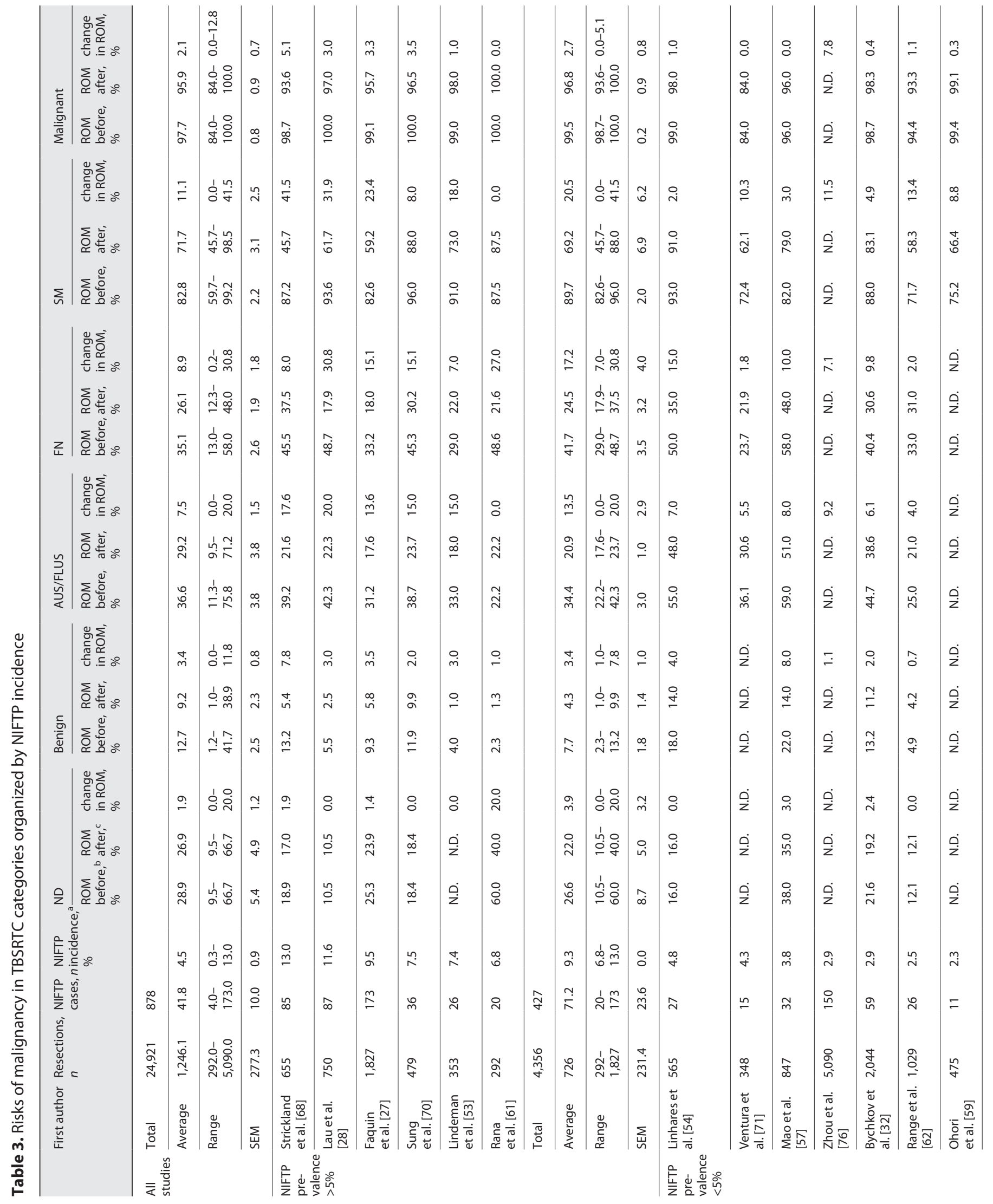




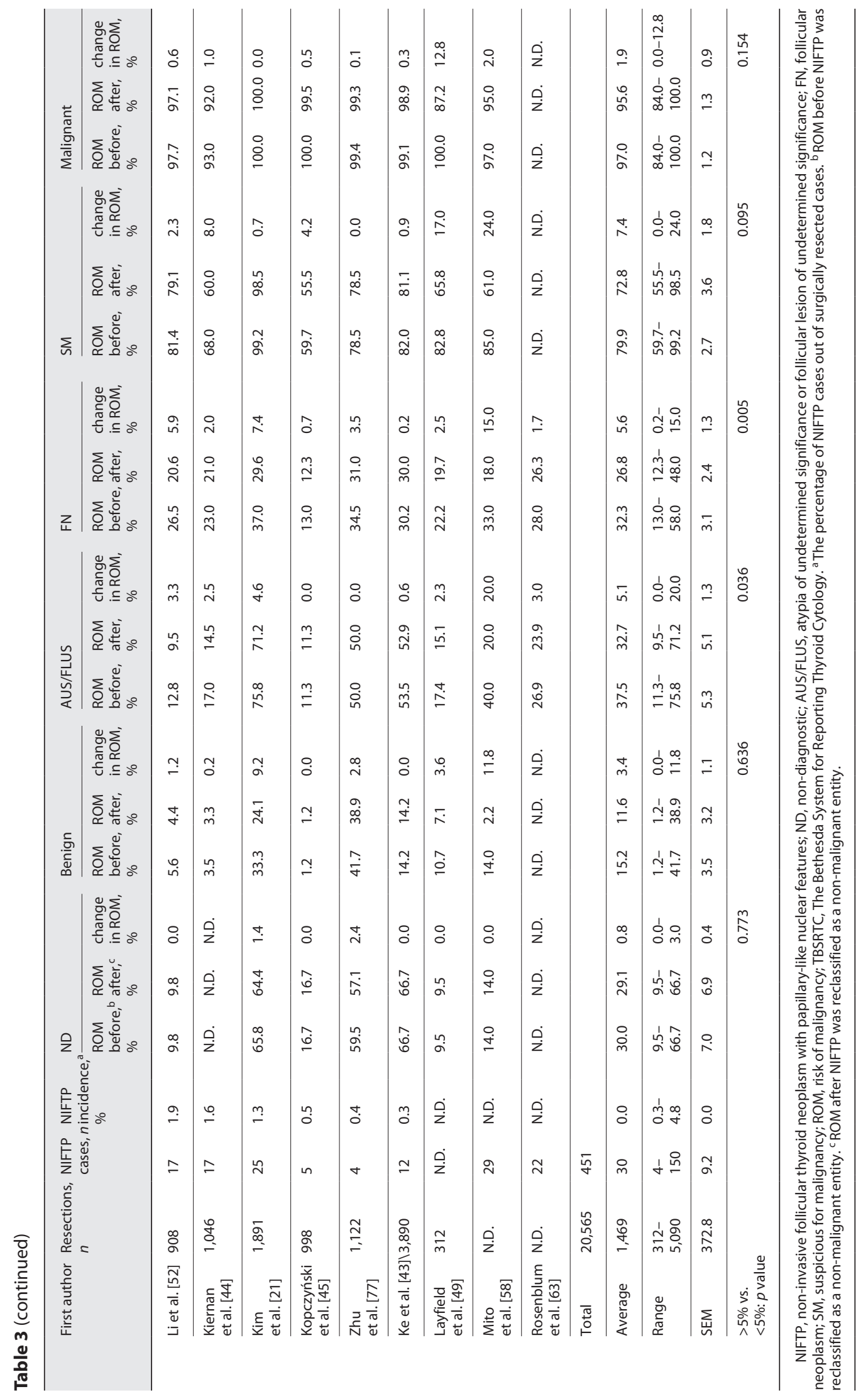


Table 4. Cytomorphological features of NIFTP, FVPTC, and PTC cases in individual studies and the ORs for occurrence

$$
\begin{array}{llll}
\text { NIFTP } & \text { FVPTC } & p \text { value: } \\
& & \text { NIFTP vs. FVPTC } & p \text { value: } \\
\text { NIFTP vs. PTC }
\end{array}
$$

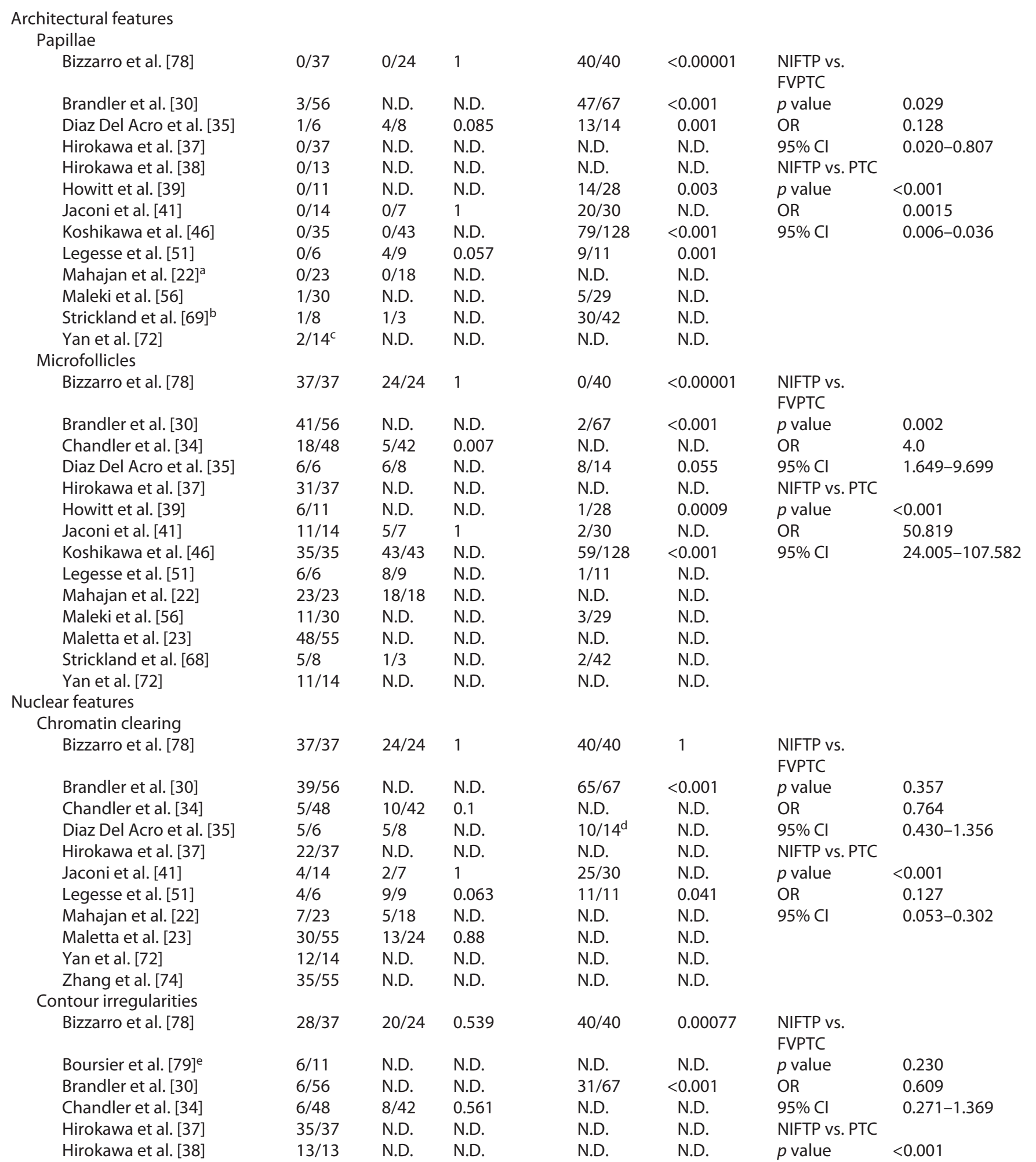


Table 4 (continued)

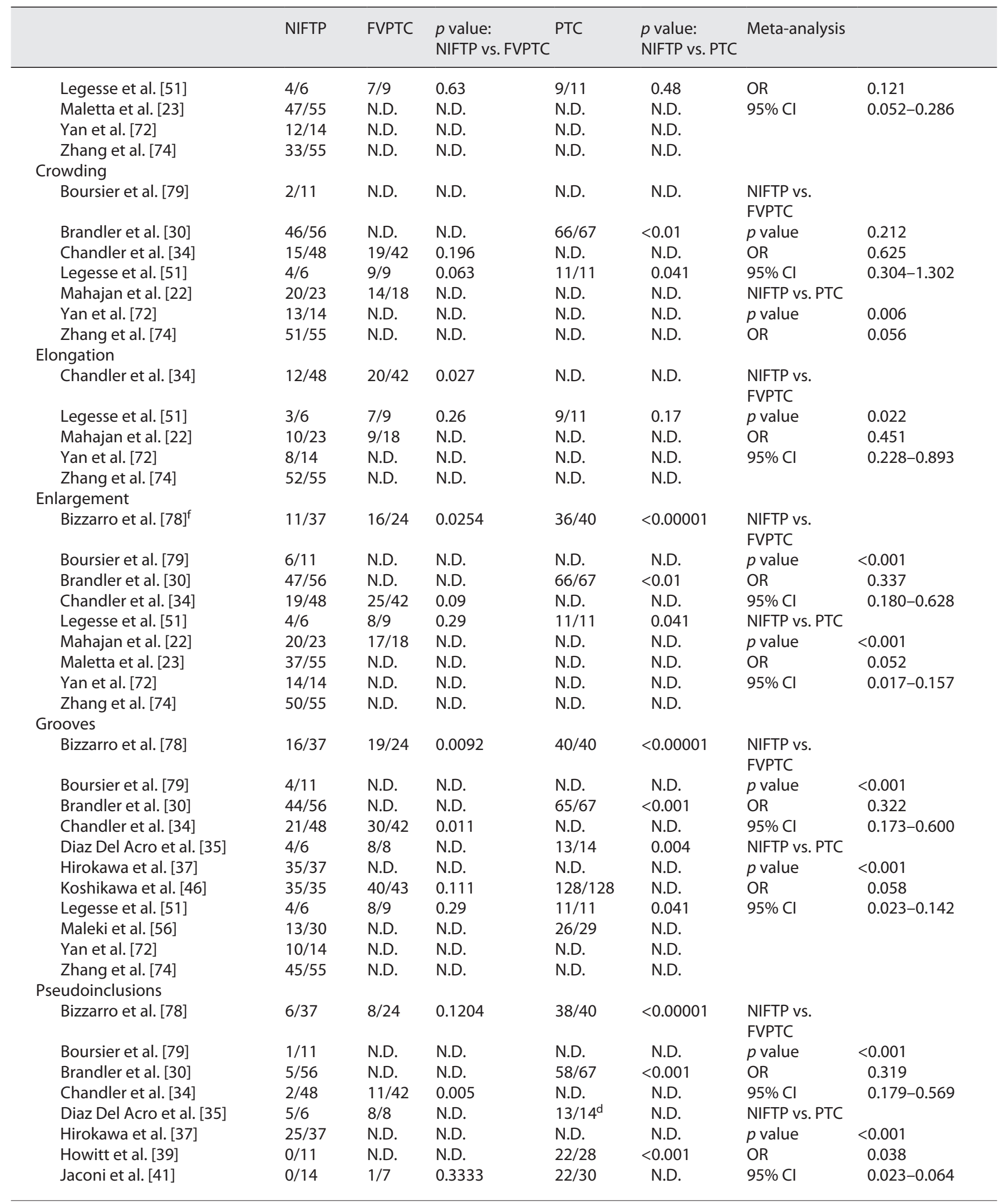


Table 4 (continued)

\begin{tabular}{|c|c|c|c|c|c|c|c|}
\hline & NIFTP & FVPTC & $\begin{array}{l}p \text { value: } \\
\text { NIFTP vs. FVPTC }\end{array}$ & PTC & $\begin{array}{l}p \text { value: } \\
\text { NIFTP vs. PTC }\end{array}$ & Meta-analysis & \\
\hline Koshikawa et al. [46] & $22 / 35$ & $28 / 43$ & 0.836 & $119 / 128$ & $<0.0 .001$ & & \\
\hline Mahajan et al. [22] & $0 / 23$ & $3 / 18$ & N.D. & N.D. & N.D. & & \\
\hline Maleki et al. [56] & $5 / 30$ & N.D. & N.D. & $20 / 29$ & N.D. & & \\
\hline Strickland et al. [69] & $1 / 8$ & $1 / 3$ & N.D. & $35 / 42$ & N.D. & & \\
\hline Zhang et al. [74] & $5 / 55^{g}$ & N.D. & N.D. & N.D. & N.D. & & \\
\hline \multicolumn{8}{|c|}{ Background features } \\
\hline \multicolumn{8}{|c|}{ Calcifications/Psammoma bodies } \\
\hline Brandler et al. [30] & $2 / 56$ & N.D. & N.D. & $15 / 67$ & $<0.01$ & $\begin{array}{l}\text { NIFTP vs. } \\
\text { FVPTC }\end{array}$ & \\
\hline Diaz Del Acro et al. [35] & $0 / 6$ & $0 / 8$ & N.D. & $0 / 14$ & N.D. & $p$ value & 0.696 \\
\hline & & & & & & OR & 0.113 \\
\hline & & & & & & $95 \% \mathrm{Cl}$ & $0.039-0.330$ \\
\hline \multicolumn{8}{|l|}{ Giant cells } \\
\hline Brandler et al. [30] & $4 / 56$ & N.D. & N.D. & $28 / 67$ & $<0.001$ & $\begin{array}{l}\text { NIFTP vs. } \\
\text { FVPTC }\end{array}$ & \\
\hline Diaz Del Acro et al. [35] & $0 / 6$ & $2 / 8$ & N.D. & $7 / 14$ & 0.032 & $p$ value & $<0.001$ \\
\hline Hirokawa et al. [37] & $1 / 37$ & N.D. & N.D. & N.D. & N.D. & OR & 0.076 \\
\hline Jaconi et al. [41] & $2 / 14$ & $4 / 7$ & 0.1196 & $25 / 30$ & N.D. & $95 \% \mathrm{Cl}$ & $0.021-0.275$ \\
\hline Koshikawa et al. [46] & $0 / 35$ & $1 / 43$ & 0.364 & $62 / 128$ & $<0.001$ & NIFTP vs. PTC & \\
\hline Legesse et al. [51] & $1 / 6$ & $0 / 9$ & 0.2 & $8 / 11$ & 0.027 & $p$ value & $<0.001$ \\
\hline Selvaggi et al. [64] & $0 / 20$ & $15 / 17$ & N.D. & N.D. & N.D. & OR & 0.016 \\
\hline Yan et al. [72] & $3 / 14$ & N.D. & N.D. & N.D. & N.D. & $95 \% \mathrm{Cl}$ & $0.003-0.081$ \\
\hline
\end{tabular}

NIFTP, non-invasive follicular thyroid neoplasm with papillary-like nuclear features; FVPTC, follicular variant of papillary thyroid carci-

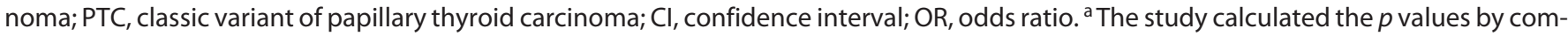
paring NIFTP to FVPTC and PTC-FP. Data of PTC-FP and the $p$ values were excluded from this table, since the classic variant of PTC was only included in this meta-analysis. ${ }^{\mathrm{b}}$ The study calculated the $p$ values by comparing NIFTP to PTC, FVPTC, and FA. Data of $p$ values were not included in this table. ' The study detected 2 NIFTP cases with pseudopapillary groups, which were described as "3-dimensional crowded sheets of follicular cells with associated vasculature that focally dissociate and mimic papillary architecture." ${ }^{\mathrm{d}}$ One of the PTC cases lacked

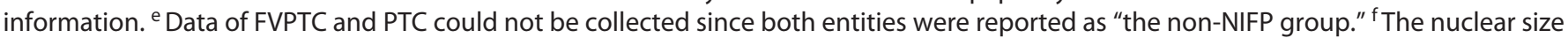
was reported as $<20 \mu \mathrm{m}$ or $>20 \mu \mathrm{m}$. The cases with nuclei larger than $20 \mu \mathrm{m}$ were categorized as cases with nuclear enlargement. ${ }^{9}$ The article stated that 5/55 (9\%) cases had definite pseudoinclusions and 23/55 (41\%) had "ill-defined pseudoinclusions."

shown in online supplement 3 (online suppl. 3, Fig. 3757). Among the 1,899 surgically resected cases with available cytological material, there were 479 NIFTP cases, 215 FVPTC cases, and 436 papillary thyroid carcinoma (PTC) cases. Other thyroid tumour entities were excluded from the analysis.

Considering architectural features, the mean presence of microfollicles was higher in NIFTP category $(78.1 \%)$ than in the FVPTC (72.6\%) or PTC (15.6\%) category. The OR of occurrence of microfollicles was statistically significantly higher in the NIFTP category than in FVPTC (OR 4.0, 95\% CI:1.649-9.699, $p=0.002$ ) or in PTC cate- gory (OR 50.819, 95\% CI: 24.005-107.582, $p<0.001$ ). Papillae were significantly less frequent in NIFTP (4.0\%) than in FVPTC $(18.2 \%$, OR $0.128,95 \%$ CI: $0.020-0.807$, $p=0.029)$ or in PTC cases $(68.0 \%$, OR $0.015,95 \% \mathrm{CI}$ : $0.006-0.036, p<0.001)$.

Giant cells were most common in PTC and observed in $7.8 \%$ of NIFTP, $34.4 \%$ of FVPTC, and $59.2 \%$ of PTC cases. The differences were statistically significant: the OR of occurrence was 0.076 between NIFTP and FVPTC (95\% CI: $0.021-0.275, p<0.001$ ) and 0.016 between NIFTP and PTC (95\% CI: $0.003-0.081, p<0.001$ ). In numbers, $4.2 \%$ of NIFTP, $2.9 \%$ of FVPTC, and $19.4 \%$ of PTC 
cases had psammoma bodies, which resulted in NIFTP having significantly less psammoma bodies than PTC (OR 0.113, 95\% CI: 0.039-0.330, $p<0.001$ ). No significant difference was found between the NIFTP and FVPTC categories (OR 1.636, 95\% CI: 0.138-19.387, $p=0.696$ ).

All nuclear features were less prominent in the NIFTP and FVPTC categories than in the PTC category. Nuclear pseudoinclusions were observed in $21.5 \%$ of NIFTP cases, in $48.6 \%$ of FVPTC cases (NIFTP vs. FVPTC: OR 0.319, 95\% CI: $0.179-0.569, p<0.001)$, and in $85.8 \%$ of PTC cases (NIFTP vs. PTC: OR 0.038, 95\% CI: 0.023-0.064, $p<0.001)$. The incidence of nuclear grooves was $66.0 \%$ in NIFTP, $96.7 \%$ in PTC, and $86.5 \%$ in FVPTC. Therefore, grooves were significantly less frequent in NIFTP than in PTC (OR 0.058, 95\% CI: 0.023-0.142, $p<0.001$ ) or FVPTC cases (OR 0.322, 95\% CI: 0.173-0.600, $p<0.001$ ). Additionally, NIFTP had significantly less nuclear enlargement than the FVPTC (OR 0.337, 95\% CI: 0.180$0.628, p<0.001$ ) or PTC (OR 0.052, 95\% CI: 0.017-0.157, $p<0.001)$ case, since the prevalence of the feature was $68.9 \%$ in NIFTP, $77.4 \%$ in FVPTC, and $96.2 \%$ in PTC cases.

Chromatin clearing was present in $59.2 \%$ of NIFTP, in $56.8 \%$ of FVPTC, and in $90.3 \%$ of PTC cases. The OR of occurrence of chromatin clearing was significantly lower in NIFTP than in PTC (OR 0.127, 95\% CI: 0.053-0.302, $p<0.001)$, whereas no significance was found comparing NIFTP with FVPTC (OR 0.764, 95\% CI: 0.430-1.356, $p=$ 0.357). In addition, nuclear crowding was significantly less apparent in NIFTP than in PTC (OR 0.056, 95\% CI: $0.007-0.430, p=0.006$ ), since it was present in $67.6 \%$ of NIFTP and in $99.3 \%$ of PTC cases. The feature was observed in $74.3 \%$ of FVPTC cases, resulting in a statistically non-significant difference between NIFTP and FVPTC cases (OR 0.625, 95\% CI: 0.304-1.302, $p=0.212$ ).

Furthermore, $64.6 \%$ of NIFTP, $60.1 \%$ of FVPTC (NIFTPvs. FVPTC: OR 0.609, 95\% CI: 0.271-1.369, $p=0.230$ ), and $76.1 \%$ of PTC cases (OR 0.121, 95\% CI: 0.052-0.286, $p<0.001)$ had nuclear contour irregularities. Nuclear elongation was visible in $54.1 \%$ of NIFTP, $58.5 \%$ of FVPTC, and $82.0 \%$ of PTC cases, and the difference was statistically significant when comparing NIFTP to FVPTC (OR 0.451, 95\% CI: 0.228-0.893, $p=0.022$ ).

To summarize, NIFTP revealed similar scores to FVPTC in many categories. Nevertheless, the meta-analysis indicated that statistically significant differences exist between NIFTP and FVPTC cases. NIFTP was more likely to have microfollicles, but papillae, giant cells, nuclear elongation, enlargement, grooves, and pseudoinclusions were more frequent in FVPTC. The presence of chroma- tin clearing, contour irregularities, crowding, and psammoma bodies did not significantly differ between NIFTP and FVPTC. Comparing NIFTP to PTC, the cytomorphological differences were more apparent. NIFTP had less papillae, chromatin clearing, contour irregularities, enlargement, grooves, pseudoinclusions, psammoma bodies, and giant cells than the PTC cases. Microfollicles were more frequent in NIFTP than in PTC.

\section{Discussion}

The present meta-analysis confirms that while being present in every category, most of the NIFTP cases belong to the AUS/FLUS, FN, and SM categories of TBSRTC. Since NIFTP is now classified as a non-invasive tumour with an extremely low malignant potential [1], the ROM decreased in all categories, with the change being the most prominent in the above-listed intermediate categories. The cytomorphology of NIFTP was similar to FVPTC, although statistically significant differences were found. The nuclear features of PTC were apparent in the NIFTP cases, but to a lesser extent than in PTC.

The large number of the analysed studies in this metaanalysis gathered comprehensive data from all around the world and enables the comparison of NIFTP between different continents. Previous studies indicated that the prevalence of NIFTP is higher in the Western countries than in Asia. Our data also support that, since the incidence of NIFTP was $4.4 \%$ in the Western countries [20, $23,26,28-31,34,35,39-42,44,45,47-49,51-60,62,64$, $65,67-72,74-76,78,79]$ and $1.3 \%$ in Asia [21, 22, 32, 33, $36-38,43,46,50,61,63,66,73,77]$. In studies that included only NIFTP and FVPTC cases, NIFTP incidence was $39.2 \%$ in the Western countries [34, 40, 47, 64] and $32.2 \%$ in Asia [22, 33, 36, 37, 50, 66, 73, 75]. In studies with all available FNA samples, the corresponding numbers were $1.9 \%[20,58,70]$ and $0.3 \%[21,43,63]$.

A study by Bychkov et al. [80] explained the incidence differences by the variation in mutation profile caused by different geographic and ethnic backgrounds in Asian patients. In addition, the differences in the interpretation of the microscopic nuclear features exist between the Western and Asian countries. They also discussed the different management approaches to intermediate thyroid nodules in Asian countries. The Asian practice tends to adopt a more conservative approach to the treatment of NIFTPlike nodules $[16,80]$. One meta-analysis considering the differences in surgical resection rate between Asian and Western countries discovered that the resection rate of 
cytologically intermediate thyroid nodules in Asia was significantly lower than in the Western countries [81]. The Japan Thyroid Association (JTA) guidelines recommend to adapt conservative clinical management for lowrisk thyroid tumours and not to decide the surgical treatment based on cytological analysis alone [16, 82]. Even though TBSRTC is widely used in Asia, the JTA guidelines undoubtedly have a significant impact on the management [83]. The lower NIFTP prevalence could be partly explained by the fact that in Asian countries, some portion of NIFTP cases are not treated surgically and thus remain undiagnosed.

A recent comprehensive meta-analysis proved the significantly lower NIFTP rates in Asian studies in comparison to North American and European countries influenced by multiple factors. However, even worldwide incidence was shown much lower (6\%) than initially estimated and their results are thus in agreement with our observations [84].

The overall distribution of TBSRTC categories followed the same trend as observed in previous meta-analyses $[27,80,85,86]$, since most of the samples belonged in the intermediate categories (AUS/FLUS 29.8\%, FN $28.0 \%$, and SM 21.2\%). However, single studies had contradicting results. In a study by Hirokawa et al. [37], $65.9 \%$ of the NIFTP cases belonged in the malignant category, with only $24.4 \%$ being in the intermediate categories. NIFTP was even more likely to be diagnosed as a malignancy on cytology than the invasive form of encapsulated FVPTC.

The 2017 version of TBSRTC included an amendment to the FN category, allowing cases that mildly represent the papillary-like nuclear features to be classified as FN [19]. Before the revision, cases with the nuclear features of PTC were excluded from the category and were most likely to be classified as AUS/FLUS or SM. This adjustment has presumably increased the portion of NIFTP cases classified as FN on cytology. Furthermore, the differences among the case inclusion criteria of the studies could have resulted in bias in the distribution of TBSRTC categories since some studies only included certain TBSRTC categories or tumour types. Still, we included all studies with available data on TBSRTC categories to provide universal data on the issue.

The average ROMs did not follow the implied ROMs of the 2017 version of TBSRTC (5-10\% for ND, $0-3 \%$ for benign, $6-18 \%$ for AUS/FLUS, $10-40 \%$ for FN, $45-60 \%$ for SM, and 94-96\% for malignant). In our meta-analysis, when NIFTP was not considered a malignant entity, the ROMs were significantly higher than estimated in the TB-
SRTC. Only FN and malignant categories fitted in the range. ND, benign, AUS/FLUS, and SM samples had higher ROMs.

This can be partly explained by the fact that the Asian studies tended to have higher ROMs in most categories when NIFTP was not considered malignant. In Asian studies, the average ROMs for each category was $49.5 \%$ for ND, $17.9 \%$ for benign, $43.1 \%$ for AUS/FLUS, $28.2 \%$ for $\mathrm{FN}, 85.7 \%$ for SM, and $99.3 \%$ for the malignant category. The corresponding numbers in studies implemented in the Western countries were $16.6 \%$ for ND, 5.8\% for benign, 23.2\% for AUS/FLUS, 25.2\% for FN, 67.1\% for $\mathrm{SM}$, and $94.8 \%$ for the malignant category. Of note, the differences between Asian and Western countries were statistically significant in 3 categories, namely AUS/ FLUS, FN, and malignant. As discussed before, the higher ROMs in Asia could result from a lower resection rate of intermediate nodules, which are usually managed by surgery only if the tumour expresses clinically worrisome features $[81,83]$. The presence of suspicious features is likely to indicate that the tumour is indeed malignant, which leads to higher percentage of malignant nodules among the resections. In addition, the incidence of NIFTP (5\% cut-off) impacts also significantly ROMs in AUS/ FLUS and FN categories.

The differences also appeared in other categories besides the intermediate ones. As an example, 1 study [77] calculated an actual ROM of $38.9 \%$ in the benign category, which is high. This was explained by the low number of resections done in the category: only 36 of 476 nodules underwent resection, and 14 of those were proven malignant during histological examination. This resulted in an overall ROM of $3.0 \%$. This explains the high rates in the ND and benign categories, since a lower number of nodules with ND or benign cytology are treated by a resection. The patients who underwent resection were mainly treated because of other suspicious clinical features, mainly worrisome ultrasound features.

The inclusion criteria of the cases in the analysed studies varied greatly, and studies with exactly the same inclusion criteria were rarely found. This leads to inaccuracy in estimating the prevalence of NIFTP among other thyroid nodules, and the incidence rates are not directly comparable. As most of the studies were implemented retrospectively, the fact that wider inclusion criteria may have led to a larger amount of NIFTP diagnoses must be considered. NIFTP is typically considered non-invasive EFVPTC, but some authors have claimed that a substantial number of NIFTP cases were previously diagnosed as benign thyroid nodules, such as adenomatous nodules or 
goitre [61]. Prior to the introduction of NIFTP, some alternative terminologies, such as "atypical adenoma," "borderline follicular tumour," and "well differentiated thyroid tumour of uncertain malignant potential," were also used in the USA although encapsulated FVPTC was the most commonly used term [87].

The subgroups of FVPTC were left out of the analysis and grouped as FVPTC as the subgroups were defined differently in various studies. This may have also distorted the results because the prevalence of NIFTP is supposedly higher in non-invasive EFVPTC than in all other types of FVPTC.

It has been noted that diagnosing PTC-like nuclear features is subjective and a common challenge for pathologists. Observer variation is possible when borderline tumours like NIFTP are the issue [16]. Even though statistically significant differences between NIFTP and FVPTC were found in this meta-analysis, differencing the entities is not so straightforward in real life. The results of a previous review indicate that differentiation of NIFTP and FVPTC in cytology is challenging, and preoperative diagnoses remain imprecise since the cytological features of the entities overlap greatly [25]. In the present meta-analysis, 10 studies compared the cytomorphology of NIFTP and FVPTC $[22,23,34,35,41,46,51,64,69,78]$. Most of these studies (80\%) found separating the 2 entities difficult $[22,23,35,41,46,51,69,78]$. A few of the studies found some statistically significant differences between the 2 entities, but stated that the separation is still challenging since the differences are not remarkable $[22,34$, $51,64,78]$. However, only 2 studies found the cytological separation possible $[34,64]$. Selvaggi et al. [64] stated that the presence of giant cells may help in differentiating the 2 entities, since they are usually observed in FVPTC. Chandler et al. [34] observed that the nuclear features of PTC were more apparent in invasive forms of FVPTC than in NIFTP, and that microfollicles and the number of pseudoinclusions could aid in the differencing the 2 entities.

On the contrary, it is possible to distinguish NIFTP/ FVPTC from PTC cytologically [14, 30, 35, 39, 41, 46, 51, $56,69,78$ ]. Brandler et al. [30] observed a statistically significant difference in many cytomorphological features: papillae and nuclear features, such as pseudoinclusions, nuclear irregularities, and chromatin clearing were more common in PTC while microfollicles being more common in NIFTP. They also discussed that the presence of microfollicles and nuclear features of PTC should alarm the diagnosis of NIFTP. Similar findings have been observed in other studies and in the present meta-analysis, and it seems like there is evidence that papillae, microfollicles, pseudoinclusions, giant cells, and psammoma bodies may guide in distinguishing NIFTP from PTC $[35,39$, $46,51,56,68,78]$. In addition, our results indicate that the numbers of other nuclear features such as nuclear enlargement, chromatin clearing, contour irregularities, grooves, and crowding are significantly higher in PTC than in NIFTP. Although pseudoinclusions were present in $21.5 \%$ of the NIFTP cases included in the present metaanalysis, they were much more common in PTC since $85.8 \%$ of PTC cases had pseudoinclusions.

Although the NIFTP criteria exclude the presence of papillae and psammoma bodies, papillae were observed in $4.0 \%$ and psammoma bodies in $4.2 \%$ of the NIFTP cases. The presence of these features in NIFTP cases could be explained by cases falsely diagnosed as NIFTP and differences in interpreting the cytomorphological features. Most studies studying the presence of papillae among NIFTP cases detected zero papillae [22, 37-39, 41, 46, 51, 78], but some authors claimed to have found a few NIFTP cases with papillae $[30,35,56,69,72]$. However, the average percentage of NIFTP cases with papillae was low among these studies (7.0\%). One of these studies [31] was published before the change in the diagnostic criteria of NIFTP in 2018 [17], and therefore followed the initial 2016 criteria of NIFTP [11]. This could explain the presence of discovered papillae among NIFTP cases, since the initial criteria allowed $<1 \%$ of the tumour architecture to be formed by papillae. Later, any presence of true papillae was prohibited, since it indicated the tumour to be PTC and capable of producing metastases. An article by Livolsi et al. [13] discussed that a vigorous FNA technique may result in degenerative changes which may replicate papillae. These, however, are not true papillae and should not be reported as papillae.

The presence of psammoma bodies was examined in 6 studies, of which $67 \%[35,46,51,69]$ found no psammoma bodies among the NIFTP cases. Nevertheless, 2 studies [30, 41] observed psammoma bodies. As psammoma bodies originate from "mummified," that is, dead papillae [88], the feature should not be observed in NIFTP.

Before the introduction of NIFTP, the treatment of non-invasive encapsulated FVPTC ranged from only lobectomy to complete thyroidectomy and radioactive iodine treatment [15]. With the presence of nuclear features of PTC, NIFTP cases were usually driven to be treated as a malignancy as a "safe practice option" [16]. Although not considered malignant, NIFTP still requires surgical nodule extraction and histological examination $[11,12$, 
$14,19,69]$. Without examining the whole tumour capsule, it is impossible to rule out invasion and to distinguish NIFTP from invasive FVPTC $[37,78]$.

The preferred treatment method for NIFTP is diagnostic lobectomy, which allows to avoid the consequences of total thyroidectomy and radioactive iodine therapy [1]. The 2015 American Thyroid Association management guidelines for adult patients with thyroid nodules and differentiated thyroid cancer stated that for FN nodules, the preferred treatment option is diagnostic lobectomy. They also discussed that clinical features, molecular tests, and sonographic findings should be taken into account on the decision on management strategy of intermediate nodules $[5,89]$. Since the preoperative cytological diagnostics of NIFTP still remain a challenge, a total thyroidectomy is an acceptable alternative for some patients [14]. Despite the popularity of lobectomy as a management strategy, the JTA guidelines still prefer active surveillance over surgical treatment of the nodule $[16,83]$.

Some authors have proposed that pathology departments should implement retrospective database reviews of nodules originally diagnosed as non-invasive encapsulated FVPTC for patients still on surveillance. If the nodules are suitable for a NIFTP diagnosis, clinicians and patients should be informed about the reclassification [15]. However, it has been noted that since the diagnosis requires thorough histological examination of the whole tumour capsule and parenchyma, definite retrospective diagnoses are rarely possible and therefore should not be made [14].

In the light of our meta-analysis, NIFTP remains a histological diagnosis which cannot be made by cytology only. Nevertheless, NIFTP has an impact on interpreting cytology. NIFTP cases are most common in the intermediate TBSRTC categories, which results in a significant decrease in ROM in the intermediate categories. Although cytomorphological features cannot be used in differentiating NIFTP from FVPTC, they may guide in separating NIFTP from PTC. Features such as pseudoinclu- sions, papillae, microfollicles, giant cells, and psammoma bodies should be taken into the account when suspicious of NIFTP. NIFTP should not have papillae. Psammoma bodies and giant cells were rarely observed in NIFTP.

\section{Statement of Ethics}

An ethics statement is not applicable because this study is based exclusively on published literature.

\section{Conflict of Interest Statement}

The authors have no conflicts of interest to declare.

\section{Funding Sources}

This research was funded by VTR grant from Pirkanmaa Hospital District and Pirkanmaa Cancer Foundation (both to I.K.), the Charles University Research Fund (Progres Q28/LF1 [UNCE 204013]) (to D.K.), and by the Charles University Research Fund (Progres Q39) (to M.L.).

\section{Author Contributions}

The following are the contributions made by the authors: conceptualization: E.H., M.L., and I.K.; methodology: E.H. and D.K.; validation: E.H. and D.K.; formal analysis: E.H. and D.K.; investigation: E.H., D.K., M.L., and I.K.; resources: I.K.; data curation: E.H., D.K., M.L., and I.K.; writing - original draft preparation: E.H. and I.K.; writing - review and editing: E.H., D.K., M.L., and I.K.; visualization: E.H. and D.K.; supervision: I.K. and M.L.; project administration: I.K.; and funding acquisition: I.K. and M.L.

\section{Data Availability Statement}

All data generated or analysed during this study are included in this article and its online supplementary material files. Further enquiries can be directed to the corresponding author (M.L.).

\section{References}

1 Lloyd R, Osamura R, Klöppel G, Rosai J. WHO classification of tumours of endocrine organs. 4th ed; 2017. p. 1-355.

2 Davies L, Welch HG. Increasing incidence of thyroid cancer in the United States, 19732002. JAMA. 2006;295(18):2164-7.

3 Ahn HS, Kim HJ, Kim KH, Lee YS, Han SJ, Kim Y, et al. Thyroid cancer screening in South Korea increases detection of papillary cancers with no impact on other subtypes or thyroid cancer mortality. Thyroid. 2016; 26(11):1535-40.
4 Ahn HS, Kim HJ, Welch HG. Korea's thyroidcancer "epidemic": screening and overdiagnosis. N Engl J Med. 2014;371(19):1765-7.

5 Haugen BR, Alexander EK, Bible KC, Doherty GM, Mandel SJ, Nikiforov YE, et al. 2015 American thyroid association management guidelines for adult patients with thyroid nodules and differentiated thyroid cancer: the American thyroid association guidelines task force on thyroid nodules and differentiated thyroid cancer. Thyroid. 2016;26(1):1-133. 
6 Hodak S, Tuttle RM, Maytal G, Nikiforov YE, Randolph G. Changing the cancer diagnosis: the case of follicular variant of papillary thyroid cancer - primum non nocere and NIFTP. Thyroid. 2016;26(7):869-71.

7 Liu J, Singh B, Tallini G, Carlson DL, Katabi $\mathrm{N}$, Shaha A, et al. Follicular variant of papillary thyroid carcinoma: a clinicopathologic study of a problematic entity. Cancer. 2006; 107(6):1255-64.

8 Rossi ED, Faquin WC. NIFTP revised: chronicle of a change foretold. Cancer Cytopathol. 2018;126(11):897-901.

9 Tallini G, Tuttle RM, Ghossein RA. The history of the follicular variant of papillary thyroid carcinoma. J Clin Endocrinol Metab. 2017;102(1):15-22.

10 Vivero M, Kraft S, Barletta JA. Risk stratification of follicular variant of papillary thyroid carcinoma. Thyroid. 2013;23(3):273-9.

11 Nikiforov YE, Seethala RR, Tallini G, Baloch ZW, Basolo F, Thompson LD, et al. Nomenclature revision for encapsulated follicular variant of papillary thyroid carcinoma: a paradigm shift to reduce overtreatment of indolent tumors. JAMA Oncol. 2016;2(8):1023-9.

12 Haugen BR, Sawka AM, Alexander EK, Bible KC, Caturegli P, Doherty GM, et al. American thyroid association guidelines on the management of thyroid nodules and differentiated thyroid cancer task force review and recommendation on the proposed renaming of encapsulated follicular variant papillary thyroid carcinoma without invasion to noninvasive follicular thyroid neoplasm with papillary-like nuclear features. Thyroid. 2017; 27(4):481-3.

13 Livolsi VA, Baloch Z. Noninvasive follicular tumor with papillary-like nuclear features: a practice changer in thyroid pathology. Arch Pathol Lab Med. 2020 Mar 30.

14 Ferris RL, Nikiforov Y, Terris D, Seethala RR, Ridge JA, Angelos P, et al. AHNS series: do you know your guidelines? AHNS endocrine section consensus statement: state-of-the-art thyroid surgical recommendations in the era of noninvasive follicular thyroid neoplasm with papillary-like nuclear features. Head Neck. 2018;40(9):1881-8.

15 Likhterov I, Osorio M, Moubayed SP, Hernandez-Prera JC, Rhodes R, Urken ML. The ethical implications of the reclassification of noninvasive follicular variant papillary thyroid carcinoma. Thyroid. 2016;26(9):116772.

16 Kakudo K. Asian and western practice in thyroid pathology: similarities and differences. Gland Surg. 2020;9(5):1614-27.

17 Nikiforov YE, Baloch ZW, Hodak SP, Giordano TJ, Lloyd RV, Seethala RR, et al. Change in diagnostic criteria for noninvasive follicular thyroid neoplasm with papillarylike nuclear features. JAMA Oncol. 2018;4(8):1125-6.

18 Alves VAF, Kakudo K, LiVolsi V, Lloyd RV, Nikiforov YE, Nosé V, et al. Noninvasive follicular thyroid neoplasm with papillary-like nuclear features (NIFTP): achieving better agreement by refining diagnostic criteria. Clinics. 2018;73:e576-4.

19 Cibas ES, Ali SZ. The 2017 Bethesda system for reporting thyroid cytopathology. J Am Soc Cytopathol. 2017;6(6):217-22.

20 Faquin WC, Wong LQ, Afrogheh AH, Ali SZ, Bishop JA, Bongiovanni $M$, et al. Impact of reclassifying noninvasive follicular variant of papillary thyroid carcinoma on the risk of malignancy in the Bethesda system for reporting thyroid cytopathology. Cancer Cytopathol. 2016;124(3):181-7.

21 Kim M, Kim JE, Kim HJ, Chung YR, Kwak Y, Park SY. Cytologic diagnosis of noninvasive follicular thyroid neoplasm with papillarylike nuclear features and its impact on the risk of malignancy in the Bethesda system for reporting thyroid cytopathology: an institutional experience. J Pathol Transl Med. 2018; 52(3):171-8.

22 Mahajan S, Agarwal S, Kocheri N, Jain D, Mathur SR, Iyer VK. Cytopathology of noninvasive follicular thyroid neoplasm with papillary-like nuclear features: a comparative study with similar patterned papillary thyroid carcinoma variants. Cytopathology. 2018; 29(3):233-40

23 Maletta F, Massa F, Torregrossa L, Duregon E, Casadei GP, Basolo F, et al. Cytological features of "noninvasive follicular thyroid neoplasm with papillary-like nuclear features" and their correlation with tumor histology. Hum Pathol. 2016;54:134-42.

24 Rosario PW, Mourão GF, Nunes MB, Nunes MS, Calsolari MR. Noninvasive follicular thyroid neoplasm with papillary-like nuclear features. Endocr Relat Cancer. 2016;23(12):893-

25 Shrestha RT, Ruanpeng D, Hennessey JV. Cytomorphology of noninvasive follicular thyroid neoplasm with papillary-like nuclear features and the impact of new nomenclature on molecular testing. Med Sci. 2019; $7(2): 15$.

26 Strickland KC, Howitt BE, Barletta JA, Cibas ES, Krane JF. Suggesting the cytologic diagnosis of noninvasive follicular thyroid neoplasm with papillary-like nuclear features (NIFTP): a retrospective analysis of atypical and suspicious nodules. Cancer Cytopathol. 2018; 126(2):86-93

27 Baloch ZW, Seethala RR, Faquin WC, Papotti MG, Basolo F, Fadda G, et al. Noninvasive follicular thyroid neoplasm with papillarylike nuclear features (NIFTP): a changing paradigm in thyroid surgical pathology and implications for thyroid cytopathology. Cancer Cytopathol. 2016;124(9):616-20.

28 Lau RP, Paulsen JD, Brandler TC, Liu CZ, Simsir A, Zhou F. Impact of the reclassification of "noninvasive encapsulated follicular variant of papillary thyroid carcinoma" to "noninvasive follicular thyroid neoplasm with papillary-like nuclear features" on the Bethesda system for reporting thyroid cytopathology. Am J Clin Pathol. 2018;149(1):504
29 Saglietti C, Bongiovanni M. The value of cytological examination in the diagnosis of noninvasive thyroid neoplasm with papillary-like nuclear features (NIFTP). J Basic Clin Med. 2017;6(1):57-60.

30 Brandler TC, Zhou F, Liu CZ, Cho M, Lau RP, Simsir A, et al. Can noninvasive follicular thyroid neoplasm with papillary-like nuclear features be distinguished from classic papillary thyroid carcinoma and follicular adenomas by fine-needle aspiration? Cancer Cytopathol. 2017;125(6):378-88.

31 Brandler T, Cho M, Wei X-J, Simms A, Levine P, Hernandez O, et al. Noninvasive follicular thyroid neoplasm with papillary like nuclear features: an interobserver study of key cytomorphological features from a large academic medical centre. Cytopathology. 2019;30(1):39-45.

32 Bychkov A, Keelawat S, Agarwal S, Jain D, Jung CK, Hong S, et al. Impact of non-invasive follicular thyroid neoplasm with papillary-like nuclear features on the Bethesda system for reporting thyroid cytopathology: a multi-institutional study in five Asian countries. Pathology. 2018;50(4):411-7.

33 Celik M, Bulbul BY, Can N, Ayturk S, Tastekin E, Sezer A, et al. Comparison of clinicopathological features in patients with noninvasive follicular thyroid neoplasm with papillarylike nuclear features and follicular variant papillary thyroid cancer. Pol Arch Intern Med. 2020;130(2):100-5.

34 Chandler JB, Colunga M, Prasad ML, Callender GG, Quinn C, Chhieng D, et al. Identification of distinct cytomorphologic features in the diagnosis of NIFTP at the time of preoperative FNA: implications for patient management. Cancer Cytopathol. 2017;125(11):865-75.

35 Díaz Del Arco C, Fernández Aceñero MJ. Noninvasive follicular thyroid neoplasm with papillary-like nuclear features: can cytology face the challenge of diagnosis in the light of the new classification? Acta Cytol. 2018;62(4): 265-72.

36 Hahn SY, Shin JH, Lim HK, Jung SL, Oh YL, Choi IH, et al. Preoperative differentiation between noninvasive follicular thyroid neoplasm with papillary-like nuclear features (NIFTP) and non-NIFTP. Clin Endocrinol. 2017;86(3):444-50.

37 Hirokawa M, Higuchi M, Suzuki A, Hayashi T, Kuma S, Miyauchi A. Noninvasive follicular thyroid neoplasm with papillary-like nuclear features: a single-institutional experience in Japan. Endocr J. 2017;64(12):1149-55.

38 Hirokawa M, Higuchi M, Suzuki A, Hayashi T, Kuma S, Miyauchi A. Prevalence and diagnostic significance of noninvasive follicular thyroid neoplasm with papillary-like nuclear features among tumors previously diagnosed as follicular adenoma: a single-institutional study in Japan. Endocr J. 2020;67(10):1071-5.

39 Howitt BE, Chang S, Eszlinger M, Paschke R, Drage MG, Krane JF, et al. Fine-needle aspiration diagnoses of noninvasive follicular variant of papillary thyroid carcinoma. Am J Clin Pathol. 2015;144(6):850-7. 
40 Ibrahim AA, Wu HH. Fine-needle aspiration cytology of noninvasive follicular variant of papillary thyroid carcinoma is cytomorphologically distinct from the invasive counterpart. Am J Clin Pathol. 2016;146(3):373-7.

41 Jaconi M, Manzoni M, Pincelli AI, Giardini V, Scardilli M, Smith A, et al. The impact of the non-invasive follicular thyroid neoplasm with papillary-like nuclear feature terminology in the routine diagnosis of thyroid tumours. $\mathrm{Cy}$ topathology. 2017;28(6):495-502.

42 Katsakhyan L, Song S, Lepe M, Shojaei H, Montone KT, LiVolsi VA, et al. Practice paradigms before and after introduction of the diagnosis-noninvasive follicular thyroid neoplasm with papillary-like nuclear features (NIFTP): an institutional experience. Endocr Pathol. 2020;31(2):174-81.

43 Ke J, Jianyong L, Ying L, Genpeng L, Linlin S, Zhihui L, et al. The use of the Bethesda system for reporting thyroid cytopathology in a Chinese population: an analysis of 13,351 specimens. Diagn Cytopathol. 2019;47(9):876-80.

44 Kiernan CM, Weiss VL, Mehrad M, Ely K, Baregamian N, Solórzano CC. New terminology noninvasive follicular neoplasm with papillary-like nuclear features (NIFTP) and its effect on the rate of malignancy at a single institution. Surgery. 2018;163(1):55-9.

45 Kopczyński J, Suligowska A, Niemyska K, Pałyga I, Walczyk A, Gąsior-Perczak D, et al. Did introducing a new category of thyroid tumors (non-invasive follicular thyroid neoplasm with papillary-like nuclear features) decrease the risk of malignancy for the diagnostic categories in the Bethesda system for reporting thyroid cytopathology? Endocr Pathol. 2020;31(2):143-9.

46 Koshikawa T, Fujita N, Ueda N, Ota Y, Sasaki E, Murakami Y, et al. Important cytological findings for distinction between follicular variant and conventional papillary thyroid carcinoma, including noninvasive follicular thyroid tumors with papillary-like nuclear features. Endocr J. 2019;66(5):475-83.

47 Larouche V, Pusztaszeri MP, Filimon S, Payne R, Hier M, Tamilia M. Preoperative prediction of non-invasive follicular thyroid neoplasm with papillary-like nuclear features: a Canadian single-centre experience. J Otolaryngol Head Neck Surg. 2020;49(1):1-8.

48 Lastra RR, Birdsong G, Hwang DH, Jorda M, Kerr DA, McGrath C, et al. Preoperative cytologic interpretation of noninvasive follicular thyroid neoplasm with papillary-like nuclear features: a 1-year multi-institutional experience. J Am Soc Cytopathol. 2018;7(2):79-85.

49 Layfield LJ, Baloch ZW, Esebua M, Kannuswamy R, Schmidt RL. Impact of the reclassification of the non-invasive follicular variant of papillary carcinoma as benign on the malignancy risk of the Bethesda system for reporting thyroid cytopathology: a meta-analysis study. Acta Cytol. 2017;61(3):187-93.
50 Lee HS, Lee JW, Park JH, Kim WS, Han HS, Lee SE. Comprehensive analysis for diagnosis of preoperative non-invasive follicular thyroid neoplasm with papillary-like nuclear features. PLoS One. 2019;14(7):e0218046-14.

51 Legesse T, Parker L, Heath J, Staats PN. Distinguishing non-invasive follicular thyroid neoplasm with papillary-like nuclear features (NIFTP) from classic and invasive follicularvariant papillary thyroid carcinomas based on cytologic features. J Am Soc Cytopathol. 2019; 8(1):11-7.

52 Li W, Sciallis A, Lew M, Pang J, Jing X. Implementing noninvasive follicular thyroid neoplasm with papillary-like nuclear features may potentially impact the risk of malignancy for thyroid nodules categorized as AUS/FLUS and FN/SFN. Diagn Cytopathol. 2018;46(2): $148-53$.

53 Lindeman BM, Nehs MA, Angell TE, Alexander EK, Gawande AA, Moore FD, et al. Effect of noninvasive follicular thyroid neoplasm with papillary-like nuclear features (NIFTP) on malignancy rates in thyroid nodules: how to counsel patients on extent of surgery. Ann Surg Oncol. 2019;26(1):93-7.

54 Linhares SM, Whitfield BW, Lee AF, Gordillo $D$, Picado O, Jeraq $M$, et al. Impact of noninvasive follicular thyroid neoplasm with papillary-like nuclear features on revised bethesda system malignancy rates at a single institution. J Surg Res. 2020;255:152-7.

55 Mainthia R, Wachtel H, Chen Y, Mort E, Parangi S, Sadow PM, et al. Evaluating the projected surgical impact of reclassifying noninvasive encapsulated follicular variant of papillary thyroid cancer as noninvasive follicular thyroid neoplasm with papillary-like nuclear features. Surgery. 2018;163(1):60-5.

56 Maleki S, Zandvakili A, Gera S, Khutti SD, Gersten A, Khader SN. Differentiating noninvasive follicular thyroid neoplasm with papillary-like nuclear features from classic papillary thyroid carcinoma: analysis of cytomorphologic descriptions using a novel machine-learning approach sara. J Pathol Inform. 2019;10(29).

57 Mao ML, Joyal T, Picado O, Kerr D, Lew JI, Farrá JC. Noninvasive follicular thyroid neoplasm with papillary-like nuclear features reclassification and its impact on thyroid malignancy rate and treatment. J Surg Res. 2018; 230:47-52.

58 Mito JK, Alexander EK, Angell TE, Barletta JA, Nehs MA, Cibas ES, et al. A modified reporting approach for thyroid FNA in the NIFTP era: a 1-year institutional experience. Cancer Cytopathol. 2017;125(11):854-64.

59 Ohori NP, Wolfe J, Carty SE, Yip L, LeBeau SO, Berg AN, et al. The influence of the noninvasive follicular thyroid neoplasm with papillary-like nuclear features (NIFTP) resection diagnosis on the false-positive thyroid cytology rate relates to quality assurance thresholds and the application of NIFTP criteria. Cancer Cytopathol. 2017;125(9):692700 .
60 Paulson VA, Shivdasani P, Angell TE, Cibas ES, Krane JF, Lindeman NI, et al. Noninvasive follicular thyroid neoplasm with papillarylike nuclear features accounts for more than half of "carcinomas" harboring RAS mutations. Thyroid. 2017;27(4):506-11.

61 Rana C, Manjunath S, Ramakant P, Singh K, Babu S, Mishra A. Noninvasive follicular neoplasm with papillary like nuclear features: a comprehensive analysis with a diagnostic algorithm. Diagn Cytopathol. 2020;48(4):33041.

62 Range DE, Jiang X. Noninvasive follicular thyroid neoplasm with papillary like nuclear features and the risk of malignancy in the Bethesda system for the reporting of thyroid cytopathology. Diagn Cytopathol. 2020; 48(6):531-7.

63 Rosenblum RC, Shtabsky A, Marmor S, Trejo L, Yaish I, Barnes S, et al. Indeterminate nodules by the Bethesda system for reporting thyroid cytopathology in Israel: frequency, and risk of malignancy after reclassification of follicular thyroid neoplasm with papillary-like features. Eur J Surg Oncol. 2019;45(7):11827.

64 Selvaggi SM. The presence of multinucleated giant cells: noninvasive follicular thyroid neoplasm with papillary-like nuclear features versus the follicular variant of papillary thyroid carcinoma. Diagn Cytopathol. 2019;47(10): 1007-10.

65 Singh R, Avila J, Jo K, Nguyen KTK, Carrillo NR, Huang EC, et al. Patients with non-invasive follicular thyroid neoplasm with papillary-like nuclear features are unlikely to have malignant preoperative cytology. Ann Surg Oncol. 2017;24(11):3300-5.

66 Sohn SY, Lee JJ, Lee JH. Molecular profile and clinicopathologic features of follicular variant papillary thyroid carcinoma. Pathol Oncol Res. 2020;26(2):927-36.

67 Song SJ, Livolsi VA, Montone K, Baloch Z. Preoperative features of noninvasive follicular thyroid neoplasms with papillary features: an analysis of their cytological, gene expression classifier and sonographic findings. $\mathrm{Cy}-$ topathology. 2017;28(6):488-94.

68 Strickland KC, Howitt BE, Marqusee E, Alexander EK, Cibas ES, Krane JF, et al. The impact of noninvasive follicular variant of papillary thyroid carcinoma on rates of malignancy for fine-needle aspiration diagnostic categories. Thyroid. 2015;25(9):987-92.

69 Strickland KC, Vivero M, Jo VY, Lowe AC, Hollowell M, Qian X, et al. Preoperative cytologic diagnosis of noninvasive follicular thyroid neoplasm with papillary-like nuclear features: a prospective analysis. Thyroid. 2016; 26(10):1466-71.

70 Sung S, Margolskee E, Chen D, TiscorniaWasserman P. Incidence of noninvasive follicular thyroid neoplasm with papillary-like nuclear features and change in risk of malignancy for "the Bethesda system for reporting thyroid cytology". J Am Soc Cytopathol. 2019; 8(3):133-40. 
71 Ventura M, Melo M, Fernandes G, Carrilho F. Risk of malignancy in thyroid cytology: the impact of the reclassification of noninvasive follicular thyroid neoplasm with papillarylike nuclear features (NIFTP). Endocr Pract. 2019;25(7):642-7.

72 Yan L, Sethi S, Park J-W. Cytologic and clinical features of NIFTP: can we diagnose based on preoperative fine needle aspiration. Diagn Cytopathol. 2019;47(12):1259-66.

73 You S-H, Lee KE, Yoo R-E, Choi HJ, Jung KC, Won J-K, et al. Prevention of total thyroidectomy in noninvasive follicular thyroid neoplasm with papillary like nuclear features (NIFTP) based on combined interpretation of ultrasonographic and cytopathologic results. Clin Endocrinol. 2018;88(1):114-22.

74 Zhang Z, Chhieng D, Harshan M, Zheng X, Zakowski M. Cytological features of noninvasive follicular thyroid neoplasm with papillary-like nuclear features (NIFTP). J Am Soc Cytopathol. 2019;8(1):5-10.

75 Zhao L, Dias-Santagata D, Sadow PM, Faquin WC. Cytological, molecular, and clinical features of noninvasive follicular thyroid neoplasm with papillary-like nuclear features versus invasive forms of follicular variant of papillary thyroid carcinoma. Cancer Cytopathol. 2017;125(5):323-31.

76 Zhou H, Baloch ZW, Nayar R, Bizzarro T, Fadda G, Adhikari-Guragain D, et al. Noninvasive follicular thyroid neoplasm with papillary-like nuclear features (NIFTP): implications for the risk of malignancy (ROM) in the Bethesda system for reporting thyroid cytopathology (TBSRTC). Cancer Cytopathol. 2018;126(1):20-6.
77 Zhu Y, Song Y, Xu G, Fan Z, Ren W. The Bethesda system for reporting thyroid cytopathology (TBSRTC): a report of 2,781 cases in a Chinese population. Chin J Cancer Res. 2020;32(2):140-8.

78 Bizzarro T, Martini M, Capodimonti S, Straccia P, Lombardi CP, Pontecorvi A, et al. Young investigator challenge: the morphologic analysis of noninvasive follicular thyroid neoplasm with papillary-like nuclear features on liquid-based cytology: some insights into their identification. Cancer Cytopathol. 2016; 124(10):699-710.

79 Boursier L, Clerc Urmes I, Garon J, Klein M, Demarquet L. Ultrasound and cytological characteristics of non-invasive follicular thyroid neoplasm with papillary-like nuclear features compared to papillary carcinomas. Ann Endocrinol. 2020;81(1):28-33.

80 Bychkov A, Jung CK, Liu Z, Kakudo K. Noninvasive follicular thyroid neoplasm with papillary-like nuclear features in Asian practice: perspectives for surgical pathology and cytopathology. Endocr Pathol. 2018;29(3): 276-88.

81 Vuong HG, Ngo HTT, Bychkov A, Jung CK, $\mathrm{Vu} \mathrm{TH}, \mathrm{Lu} \mathrm{KB}$, et al. Differences in surgical resection rate and risk of malignancy in thyroid cytopathology practice between western and Asian countries: a systematic review and meta-analysis. Cancer Cytopathol. 2020; 128(4):238-49.

82 Kakudo K, Kameyama K, Miyauchi A, Nakamura $\mathrm{H}$. Introducing the reporting system for thyroid fine-needle aspiration cytology according to the new guidelines of the Japan thyroid association. Endocr J. 2014;61(6): $539-52$.
83 Kakudo K, Higuchi M, Hirokawa M, Satoh S, Jung CK, Bychkov A. Thyroid FNA cytology in Asian practice active surveillance for indeterminate thyroid nodules reduces overtreatment of thyroid carcinomas. Cytopathology. 2017;28(6):455-66.

84 Rana C, Vuong HG, Nguyen TQ, Nguyen HC, Jung CK, Kakudo K, et al. The incidence of noninvasive follicular thyroid neoplasm with papillary-like nuclear features: a meta-analysis assessing worldwide impact of the reclassification. Thyroid. 2021.

85 Ruanpeng D, Cheungpasitporn W, Thongprayoon C, Hennessey JV, Shrestha RT. Systematic review and meta-analysis of the impact of noninvasive follicular thyroid neoplasm with papillary-like nuclear features (NIFTP) on cytological diagnosis and thyroid cancer prevalence. Endocr Pathol. 2019; 30(3):189-200.

86 Nishino M. How is noninvasive follicular thyroid neoplasm with papillary-like nuclear features (NIFTP) shaping the way we interpret thyroid cytology? J Am Soc Cytopathol. 2019; 8(1):1-4.

87 Seethala RR, Baloch ZW, Barletta JA, Khanafshar E, Mete O, Sadow PM, et al. Noninvasive follicular thyroid neoplasm with papillarylike nuclear features: a review for pathologists. Mod Pathol. 2018;31(1):39-55.

88 Johannessen JV, Sobrinho-Simões M. The origin and significance of thyroid psammoma bodies. Lab Invest. 1980;43(3):287-96.

89 Haugen BR. 2015 American thyroid association management guidelines for adult patients with thyroid nodules and differentiated thyroid cancer: what is new and what has changed? Cancer. 2017;123(3):372-81. 